Federal Reserve Bank of New York

Staff Reports

\title{
Insolvency after the \\ 2005 Bankruptcy Reform
}

\author{
Stefania Albanesi \\ Jaromir Nosal
}

Staff Report No. 725

April 2015

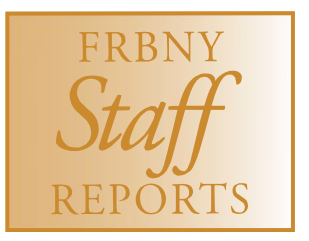

This paper presents preliminary findings and is being distributed to economists and other interested readers solely to stimulate discussion and elicit comments. The views expressed in this paper are those of the authors and do not necessarily reflect the position of the Federal Reserve Bank of New York or the Federal Reserve System. Any errors or omissions are the responsibility of the authors. 
Insolvency after the 2005 Bankruptcy Reform

Stefania Albanesi and Jaromir Nosal

Federal Reserve Bank of New York Staff Reports, no. 725

April 2015

JEL classification: D12, D14, E65, K35

\begin{abstract}
Using a comprehensive panel dataset on U.S. households, we study the effects of the 2005

Bankruptcy Abuse Prevention and Consumer Protection Act (BAPCPA), the most substantive reform of personal bankruptcy in the United States since the Bankruptcy Reform Act of 1978. The 2005 legislation introduced a means test based on income to establish eligibility for Chapter 7 bankruptcy and increased the administrative requirements to file, leading to a rise in the opportunity cost and, especially, the financial cost of filing for bankruptcy. We study the effects of the reform on bankruptcy, insolvency, and foreclosure. We find that the reform caused a permanent drop in the Chapter 7 bankruptcy rate relative to pre-reform levels, owing to the rise in filing costs associated with the reform, which can be interpreted as resulting from liquidity constraints. We find that the decline in bankruptcy filings resulted in a rise in the rate and persistence of insolvency as well as an increase in the rate of foreclosure. We find no evidence of a link between the decline in bankruptcy and a rise in the number of individuals who are current on their debt. We document that these effects are concentrated at the bottom of the income distribution, suggesting that the income means tests introduced by BAPCPA did not serve as an effective screening device. We show that insolvency is associated with worse financial outcomes than bankruptcy, as insolvent individuals have less access to new lines of credit and display lower credit scores than individuals who file for bankruptcy. Since bankruptcy filings declined much more for low-income individuals, our findings suggest that, for this group, BAPCPA may have removed an important form of relief from financial distress.
\end{abstract}

Key words: personal bankruptcy, insolvency, foreclosure

Albanesi: Federal Reserve Bank of New York (e-mail: stefania.albanesi@ny.frb.org). Nosal: Columbia University (e-mail: jnosal@ columbia.edu). For helpful comments, the authors thank Christopher Conlon, Luigi Guiso, David Lucca, Neale Mahoney, Don Morgan, Claudia Olivetti, Christoph Rothe, Joseph Tracy, Jonathan Vogel, and seminar participants at Columbia University, the Federal Reserve Bank of New York, the Society for Economic Dynamics (SED) Annual Meetings, the National Bank of Poland, the NBER Summer Institute, the NBER Household Finance conference "Research Findings and Implications for Policy," the 13th Workshop on Macroeconomic Dynamics, and the University of Waterloo. They are also grateful to Zachary Bleemer and Matthew Ploenzke for excellent research assistance. The views expressed in this paper are those of the authors and do not necessarily reflect the position of the Federal Reserve Bank of New York or the Federal Reserve System. 


\section{Introduction}

This paper studies the impact of the 2005 Bankruptcy Abuse Prevention and Consumer Protection Act on bankruptcy, insolvency and foreclosure behavior of U.S. households. The Act is the single most important piece of legislation regarding personal bankruptcy since the Bankruptcy Reform Act of 1978. The main provision of the law were to introduce an income means tests to determine eligibility for Chapter 7 bankruptcy ${ }^{1}$ The new law also increased the cost of filing in a variety of ways. It raised the amount of paperwork required and mandated that filers attend compulsory credit counseling classes at their own expense. It also introduced a new provision that attorneys can now be held personally liable for inaccuracies in the filing.

One of the major consequences of the law's new requirements was a sizable rise in attorney fees for bankruptcy cases. Median attorney fees increased by $38 \%$ for Chapter 7 filers, from an average of $\$ 663$ dollars pre-reform to $\$ 986$ post-reform $2^{2}$ Given the extreme low incomes of filers pre-reform and the fact that bankrupt households are often cash poor $3^{3}$ cost changes of this magnitude can significantly affect potential filers' options. Thus, the reform can serve as a natural laboratory in order to asses the impact costs on bankruptcy and delinquent behavior. As such, it can provide valuable insights into a long-standing debate on the balance between the social insurance provided by the bankruptcy code versus the moral hazard necessarily associated with any such insurance.

Our analysis is based on anonymous administrative credit file data from a nationally representative panel of U.S. individuals from 1999 to 2013. These data allow us to observe the drop in bankruptcies and the changing characteristics of bankrupts, as well as the behavior of financially distressed individuals who post-2005 decide not to file for bankruptcy. A large literature following BAPCPA's introduction studies its effects on the bankruptcy filing rate and on the characteristics of those who file for bankruptcy, based mainly on surveys of filers or bankruptcy courts records.4 Our analysis is the first to shed light on the outcomes of the individuals who no longer file for bankruptcy post-reform. Specifically, we derive three sets of results.

\footnotetext{
${ }^{1}$ Individuals who fail to pass the income means test can still file for Chapter 7 in their debt to income ratio is high enough.

${ }^{2}$ See Jones (2008), Lupica (2012), White (2007).

${ }^{3}$ Documented for example in Mann and Porter (2009) and Gross, Notowidigdo, and Wang (2012).

${ }^{4}$ In a leading study, Lawless et al. (2008) use the 2007 Consumer Bankruptcy Project to document the changes in the characteristics of bankrupts when compared with data from similar studies in 1981, 1991 and 2001. They find that the the Act did not change the income composition of bankrupts but increased their in-bankruptcy debt and the length of time before filing. One limitation of these studies is that they focus solely on a small sample of bankrupt individuals from a selected number of states.
} 
First, we show, controlling for a comprehensive set of court district level economic and regulatory variables, that BAPCPA is associated with a large drop in Chapter 7 bankruptcy filings, a much smaller drop in Chapter 13 filings, a rise in foreclosures, and a rise in the fraction of individuals who are insolvent-have severe credit delinquencies but do not file for bankruptcy. Using a novel income imputation procedure, we show that the strength of these responses is larger for individuals with income below the national median. This finding suggests that the means test on income did not play a major role in driving the responses to the reform, particularly the decline in the bankruptcy rate, while it is consistent with the rise in the monetary costs of filing playing an important role.

Second, we exploit the geographical variation in attorney filing fees across U.S. districts pre- and post-reform to quantify the role of the monetary filing cost on bankruptcy behavior. We find that higher filing fees are strongly negatively related to Chapter 7 bankruptcies, but not to Chapter 13 bankruptcies. A major difference between these two chapters is that fees for Chapter 7 have to be paid up-front, while fees for Chapter 13 can be paid in installments during the bankruptcy discharge period. Since the fees for both chapters increased by similar magnitudes post-reform, this suggests that the up-front nature of the filing cost for Chapter 7 bankruptcy plays a crucial role in discouraging potential filers, supporting the interpretation that these individuals are liquidity constrained!5 We also show that the response to the filing cost change associated with the reform is stronger for individuals below the median national income, confirming the hypothesis that the rise in filing costs, not the means test for income, was the main mechanism through which BAPCPA affected bankruptcy behavior.

Finally, we document the substitution patterns from Chapter 7 bankruptcy to foreclosure, insolvency and being current on all payments using district level variation. We find a strong substitution from bankruptcy to foreclosure and insolvency, but no impact on the frequency of individuals who are current on all debt.

Our analysis concentrates on studying the behavior of individuals who enter a new spell of financial distress, which we identify with a new delinquency or a new insolvency after 8 quarters with a clean record. A delinquency occurs if a payment is 30, 60 or 90 days late on any account, while an insolvency occurs if a payment is 120 days or more late or charged off on any account. Exploiting the panel dimension of our data, we estimate the probability of transitioning from a new spell of financial distress to Chapter 7 and Chapter 13 bankruptcy, insolvency and foreclosure. To do so, we calculate frequency distributions, leading to estimates of the transition probabilities across these states, which we aggregate

\footnotetext{
${ }^{5}$ It would be difficult for filers to borrow to finance Chapter 7 filing costs, since debts is contracted close enough to filing date can be considered fraudulent due to lack of intent to repay.
} 
at the court district level.

Our first set of findings regard the time variation in these transition probabilities in the aggregate, controlling for district-level economic and regulatory factors ${ }^{6}$ This exercise captures the timing and direction of the responses to the reform, and it guides the rest of our analysis. We find that, upon implementation of the Act, the transition into Chapter 7 bankruptcy drops by 60 log points from a new delinquency and by 80 log points from a new insolvency. Concurrently, the transition from a new delinquency to insolvency without foreclosure rises by $20 \log$ points and the transition to foreclosure (without bankruptcy) rises by $75 \log$ points after the reform, while the transition to current declines by 10 log points. Similarly, the transition from a new insolvency to foreclosure rises by 40 log points after the reform. We also find a very modest drop of the transition from a new delinquency or insolvency to Chapter 13 bankruptcy. This implies that as a consequence of the reform, Chapter 13 filings grow as a fraction of all filings, mostly as a result of the large drop in Chapter 7 filings. All the documented responses are stronger for low income individuals, which suggests a role of the rise in the monetary cost of filing for bankruptcy.

These findings suggest that individuals who would have filed for bankruptcy pre-2005 are now pushed into insolvency and foreclosure and find it more difficult to pay off their debts and return to being current. We interpret the rise of the transition into foreclosure from a new delinquency and a new insolvency as resulting from financially distressed individuals resorting to default on secured debt, having lost the option to default on their unsecured debt.7

BAPCPA increased the cost of filing for bankruptcy in a variety of ways. In particular, the rise in paperwork and the introduction of personal liability for attorneys in case of inaccuracies led to a sizable increase in attorney fees. The next step in our analysis focusses on the role of the rise in these fees, which account for about $75 \%$ of the total cost of filing for bankrutpy (see Lupica (2012)). Crucially, even though the Act is a federal law, both the initial level of the fees and the change associated with the reform exhibit sizable cross-district variation. We exploit this geographic variation to examine the mechanism through which BAPCPA led to a decline in bankruptcy filings.

We adopt a difference-in-difference approach to quantify the effect of the cost on bankruptcy, insolvency and foreclosure. Specifically, we first examine the quantitative re-

\footnotetext{
${ }^{6}$ We include a number of economic covariates, such as unemployment, personal disposable income, house prices and their four quarter change. The state level regulatory controls include information on homestead exemption, wage garnishment and foreclosure regulation.

${ }^{7}$ Given the homestead exemption, most bankrupt households can retain their main residence and continue to service real estate debt associated with that property.
} 
sponse of bankruptcy rates to the reform through the change in the filing fees at the district level. We then estimate the degree of substitution from bankruptcy to insolvency and foreclosure.

We find a statistically and economically significant impact of attorney fees on transitions into Chapter 7 bankruptcy. Our estimates imply that moving from the 25th to the 75th percentile of the cost distribution increases the drop in Chapter 7 bankruptcy by $18 \log$ points. When we estimate the elasticity of the flow into bankruptcy separately pre- and post-reform, we find that the relationship is stable-implying that the overall increase in the costs post-reform will drive bigger variation in bankruptcy outcomes. We show that cost changes are not driven by differences in endogenous bankruptcy outcomes, economic variables or regulatory variables, leading us to conclude that the variation in these costs is plausibly exogenous. As a robustness, we also provide instrumental variable analysis. Specifically, we instrument the cost change with the political preferences of the judges, or alternatively, we instrument the post-reform costs with their value pre-reform. Both strategies confirm our baseline results.

We repeat our analysis distinguishing among individuals above and below the median national income, and we find that all the effects are much stronger for individuals with income below the median. This suggests that the high cost of filing for bankruptcy postreform mostly drove the response. These findings also suggest that the income means test for Chapter 7 introduced by the reform was not the main screening mechanism inducing the reduction in Chapter 7 bankruptcy filings. This interpretation is also confirmed by the behavior of Chapter 13 bankruptcy, for which we find no relation between the change in Chapter 13 attorney fees and the response of the filing rate to the reform. An important difference between Chapter 7 and 13 bankruptcy is that Chapter 7 filing costs need to be paid upfront, while they can be part of the court mandated repayment plan for Chapter 13 bankruptcy. Given this difference, the lack of relation between the response of Chapter 13 filings and the change in associated attorney fees post-reform is consistent with the hypothesis that liquidity constraints drive the response of Chapter 7 filings to the reform.

The last step in our analysis is to quantify the substitution from bankruptcy to other outcomes post-reform. Specifically, controlling for economic and regulatory factors, we estimate the district-level mean response of transition probabilities from new insolvencies to foreclosure, insolvency, bankruptcy and current at 4 and 8 quarter horizons. For these outcomes, we find that a larger drop in the transition into bankruptcy is associated with a statistically and economically sizable increase in the persistence of insolvency and a larger transition probability into foreclosure. At the 4 quarter horizon, the median estimated drop 
of the transition into bankruptcy (66\%) increases the persistence of the insolvency state by $3.3 \%$ and the transition into foreclosure by $34 \%$. Interestingly, we do not find a relation between the drop in the flows into bankruptcy and the flows into current. There is also no evidence of a deterrence effect of the law, as the persistence of staying current is not related to the drop in flows to bankruptcy.

Our findings indicate that the decline in Chapter 7 bankruptcy associated with the reform is associated with a rise in insolvency, with and without foreclosure. It is therefore important to determine whether this response is consequential for households. To examine this question, we consider cohorts of newly insolvent individuals, distinguishing those who go bankrupt in the 8 quarters after the new insolvency and those who don't. We then examine the behavior of several financial indicators for a 2 year window around that new insolvency. Among individuals who become newly insolvent at the same date, we find that the individuals who will eventually go bankrupt initially have lower credit scores, suggesting that they are negatively selected. However, they experience a sharp boost in their credit score after bankruptcy, whereas credit scores recover at a much slower pace for individuals who remain insolvent. One quarter after bankruptcy, the credit score of bankrupt individuals exceeds the credit score of insolvent individuals 1 quarters after insolvency by 40-80 points. In addition, those who go bankrupt open new unsecured accounts post-bankruptcy at a higher rate (by around 15 percentage points) than those who don't go bankrupt, while the number of inquiries is very similar across the two groups. This indicates a difference in access to credit, not demand for credit. We conclude from this evidence that the ability to file for Chapter 7 bankruptcy is associated with better access to credit, and while both insolvency and bankruptcy are forms of default, the debt discharge associated with bankruptcy leaves filers in a better financial position than individuals who become insolvent in similar circumstances.

Our analysis has wide-ranging implications for the design of policies regulating consumer credit and bankruptcy. First, we show that a sizable group of individuals exists that does not file for bankruptcy, but seems unable to pay off their debts. These individuals are concentrated at the bottom of the income distribution, and therefore they are the ones who would be expected to benefit most from the relief offered by personal bankruptcy. Our analysis suggests that any policies affecting the financial cost of filing for bankruptcy will impact disproportionately these individuals. Second, we show that there is a strong substitution between Chapter 7 bankruptcy and foreclosure, and hence regulating either one of these institutions is likely to impact the other in significant ways. Finally, we provide a systematic analysis of the consequences of failure to file for bankruptcy for insolvent individuals, which include lower access to credit and lower credit scores. 
One of the main goals of personal bankruptcy is to provide an incentive compatible insurance scheme against streams of negative income shocks that make repayment of debts contracted in better times too onerous or impossible for the debtor. Our finding that bankruptcy filings have declined mostly for low income, possibly liquidity constrained individuals, resulting in a substantial rise in the rate and persistence of insolvency suggests that the Act may have removed this form of insurance for these households. It also suggests that the income means test that was introduced to ameliorate possible moral hazard associated with Chapter 7 bankruptcy was not effective. Further, the fact that the decline in bankruptcy filings was associated with a rise in the foreclosure rate implies that formal default on unsecured debt has been replaced to a substantial degree by default on secured debt, possibly exacerbating the housing crisis.

The rest of the paper is organized as follows. Section 2 provides a short overview of the bankruptcy law in the U.S., including the changes implied by the 2005 reform. Section 3 reports our estimates of transition probabilities into various delinquency states. Section 4 describes our cross-district regression analysis. Section 6 examines the consequences of the substitution into insolvency from bankruptcy and concludes. The Appendix presents additional details of our results.

\section{The 2005 Bankruptcy Reform}

Households in financial distress in the U.S. can resolve their insolvency by filing for bankruptcy. Upon filing, debtors obtain immediate relief from all collection efforts, including direct communication, lawsuits and wage garnishment. Most unsecured debt is dischargeable, excluding taxes, alimony and child support obligations, student loans and debt obtained by fraud.

Chapter 7, usually called 'straight bankruptcy' or 'fresh start' option, is the most commonly used bankruptcy procedure - up to 2005 a remarkably stable $70 \%$ of bankruptcies were Chapter 7 bankruptcies. Under Chapter 7, filers submit a list of all their assets to the courts. The part of the assets which exceeds certain exemption level ${ }^{8}$ is then used to satisfy unsecured creditors. The rest of the debts are discharged, and debtors are not obliged to use future income for debt repayment (hence 'fresh start'). Chapter 7 bankrupts are not allowed to re-file another Chapter 7 case for the next 6 years (increased to 8 by the 2005 Act), and

\footnotetext{
${ }^{8}$ Asset exemptions are determined at the state level. Exempt assets may include clothing, furniture, 'tools of trade', a vehicle up to some value. Additionally, most states have homestead exemptions, which protect equity in the house up to a state-level specified limit.
} 
have a bankruptcy flag on their credit report for 10 years after filing.

Under Chapter 13, bankrupts keep all of their assets, but must use their future income to repay part of their unsecured debt 9 . Debtors propose their own repayment plans (pre-2005, post-2005 they must use all of their law-defined disposable income to pay off debts) lasting 3-5 years, with the restriction that the total proposed repayment cannot be lower than the value of their non-exempt assets under Chapter 7. A Chapter 13 bankruptcy is considered discharged after the debt repayment plan has been executed, and the Ch.13 bankruptcy flag stays on the credit record for 7 years after discharge.

Historically, ever since the introduction of the bankruptcy law as we know it, both unsecured debt levels and bankruptcy rates have been rapidly rising over time (the trend extending all the way back to 1978), which gave rise to numerous studies on the sources of the ris ${ }^{10}$, as well as active policy discussion on the efficiency of existing law. That discussion resulted in the 2005 bankruptcy reform.

The BAPCPA was signed by president George W. Bush on April 20, 2005 and applied to bankruptcy cases filed on or after October 17, 2005. It introduced several major changes to bankruptcy regulation which increased the burden, financial and otherwise, of filing for bankruptcy protection. Among the most notable new features are the introduction of an income 'means test' and sufficient indebtedness tests to determine eligibility for filing for Chapter 7 bankruptcy. Specifically, to be eligible to file for Chapter 7, individuals who fail the means test must have (i) their monthly income net of allowable expenses calculated according to IRS rules be less than $\$ 166.67$ per month and (ii) their net monthly income multiplied by 60 be less than 25 percent of their unsecured debt. In addition, Ch. 13 filers lost the ability to propose their own repayment plans. Overall, there was also a significant increase in the filing documentation burden for both chapters. Filers must file detailed financial information with the bankruptcy court, essentially showing proof of sufficient indebtedness and inability to pay, as well as good faith attempts at paying back. Bankruptcy lawyers must certify the accuracy of the information, and are subject to strict fines in case inaccuracies are detected. In addition, the Act requires debtors to enroll in a credit counseling class before they file and a financial management course before their debts are discharged.

\footnotetext{
${ }^{9}$ More debts are dischargeable under Chapter 13 than Chapter 7, including some car loans and debts incurred by fraud or cash advances shortly before filing (the so called 'super discharge').

${ }^{10}$ Including Athreya (2002), Domowitz and Eovaldi (1993), Domowitz and Sartain (1999), Gross and Souleles (2002), Fay, Hurst, and White (2002), Livshits, MacGee, and Tertilt (2007), Livshits, MacGee, and Tertilt (2010).
} 
The cost change The sum of these provisions resulted in a significant rise in the cost of filing for bankruptcy. The total out-of-pocket cost of filing for bankruptcy increased from $\$ 600$ and $\$ 1600$ for Chapters 7 and 13 to $\$ 2500$ and $\$ 3500$, respectively (White (2007), also consistent with findings in Lupica (2012)). In our study, we will focus on attorney fees and their increase associated with the reform. Attorney fees comprise $75 \%$ of the total financial cost of filing for bankruptcy (Lupica (2012)), and rose on average 35\% after the reform.

\section{Transitions}

We use the Federal Reserve Bank of New York's Consumer Credit Panel/Equifax Data (CCP), which is an anonymous longitudinal panel of individuals with quarterly frequency, starting in 1999:Q1 and ending in 2013:Q3. The panel comprises a 5\% random sample of all individuals who have a credit report with Equifax. The data is described in detail in Lee and van der Klaauw (2010). In our analysis, we use a $1 \%$ sample, including information on approximately 2.5 million individuals in each quarter.

The data contains over 600 variables ${ }^{11}$ allowing us to track all aspects of individuals' financial liabilities, including bankruptcy and foreclosure, mortgage status, detailed delinquencies, various types of debt, with number of accounts and balances. Apart from the financial information, the data contains individual descriptors such as age, ZIP code and credit score. The variables included in our analysis are described in detail in Appendix A.

\subsection{The Effects of BAPCA over Time}

To understand the path into bankruptcy and financial distress, we estimate the probability of transitioning between a set of mutually exclusive financial states, for different horizons. This approach uses to the full extent the panel nature of the data and allows us to identify the timing and magnitude of the response to the reform. In any given quarter, an individual's state is Current, if there are no delinquencies of any type in her record for that quarter, and no bankruptcy or foreclosure flags. An individual's state is Delinquent, if she has accounts that are 30,60 or 90 days delinquent. An individual's state is Insolvent if she has any debt that is 120 days plus delinquent or in charge-off 12 An individual is Bankrupt, if she displays a bankruptcy flag, or in Foreclosure if she displays a foreclosure flag. The bankruptcy flag is activated by a new bankruptcy filing, where we distinguish between Ch. 7 and Ch. 13.

\footnotetext{
${ }^{11}$ For data dictionary, go to http://www . newyorkfed.org/householdcredit/2013-q3/data/pdf/data_ dictionary_HHDC.pdf.

${ }^{12}$ Student debt is not dischargeable in bankruptcy, and is excluded from the analysis.
} 
The bankruptcy flag for Ch. 7 stays on the record for 10 years. The one for Ch. 13 stays on the record for 7 years after the payment plan has been completed. The foreclosure flag is activated by a new foreclosure record on the individual's account, and lasts for 7 years from its first appearance.

We estimate the 4-quarter-ahead transition probabilities across these states for each quarter in the sample, starting from a new delinquency and a new insolvency. A new delinquency is defined as a state in which in an individual is delinquent, after 8 quarters without delinquencies, insolvencies, bankruptcy or foreclosure. We focus on the transitions from a new delinquency to identify the possible start of a spell of financial distress. Approximately, $0.8 \%$ of the population becomes newly delinquent in each quarter in our sample. We also consider transitions from a new insolvency, defined as a state in which an individual becomes insolvent after 8 quarters of no insolvencies, with no bankruptcy or foreclosures. A new insolvency captures the start of a spell of more severe financial distress. Approximately 0.6\% of the overall population becomes newly insolvent in each quarter of our sample, and this percentage is stable over time.

To eliminate the effects of business cycles and other economic factors possibly driving the transitions from a new delinquency or insolvency to bankruptcy and other outcomes of interest, we estimate the following regression:

$$
y_{i t}=\sum_{s(t) \neq 0} \beta_{s(t)} I_{s(t)}+\gamma_{i}+\phi X_{i t}+\epsilon_{t}
$$

where $y_{i t}$ is the log transition in district $i$ at quarter $t, \beta_{s(t)}$ capture time effects, relative to base period $0, I_{s(t)}$ is an indicator for period $s$ (year or quarter), $\gamma_{i}$ denote district effects, and $X_{i t}$ denotes a set of economic controls, in logs ${ }^{13}$

The estimated $\beta_{s(t)}$ capture the timing and magnitude of the response to the reform. They are also able to detect the presence of any pre-existing trends in the transitions of interest. We report the estimates of the time effects for the yearly specification below, starting from the transitions from a new delinquency. 14 Figure 1 reports the estimate for the time effects for the transitions from a new delinquency.

The top left panel displays the estimates for the transitions into Ch. 7 bankruptcy, which show a sizable and permanent drop in the transitions. The drop is approximately equal to

\footnotetext{
${ }^{13}$ These include district level personal income, unemployment rate and home price index, as well as the 4 quarter change in these variables.

${ }^{14}$ The estimates of the coefficients for the controls and for the quarterly specification do not change the conclusions of this section, and are available from the authors upon request.
} 


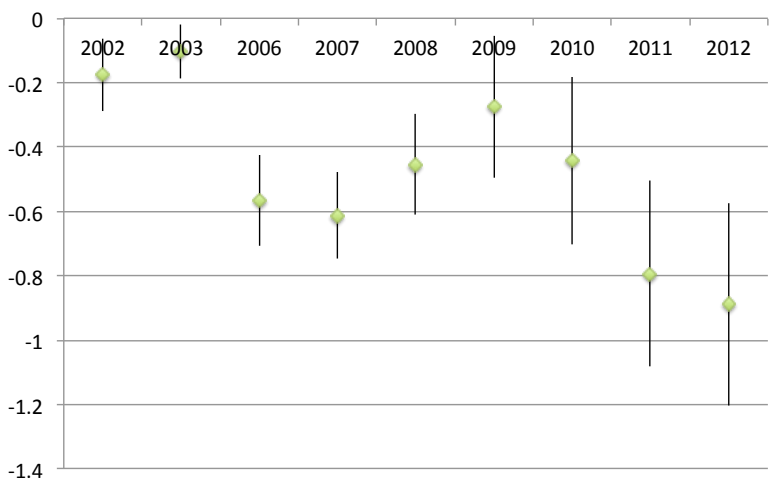

(a) Ch 7 bankruptcy

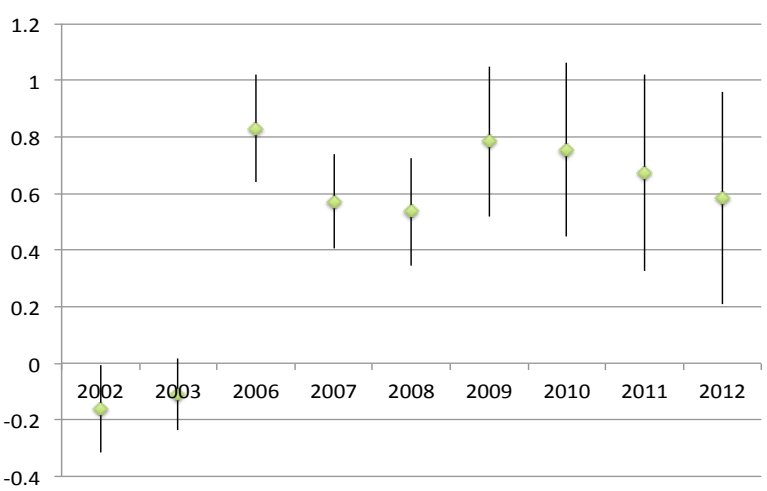

(c) Foreclosure

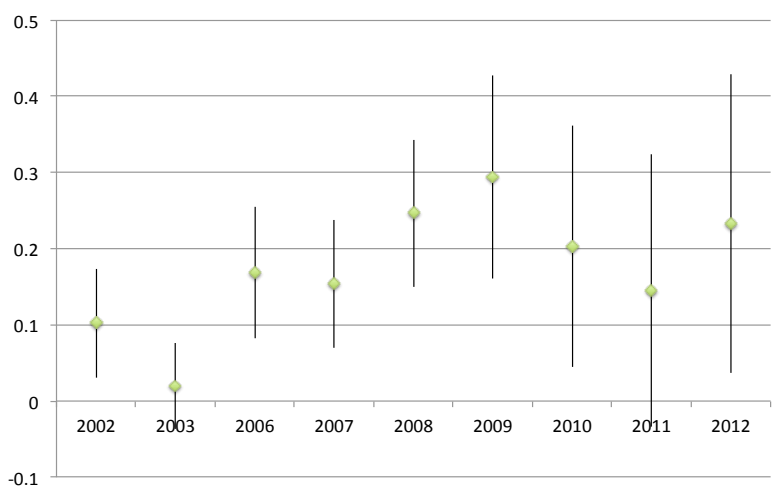

(b) New insolvency without foreclosure

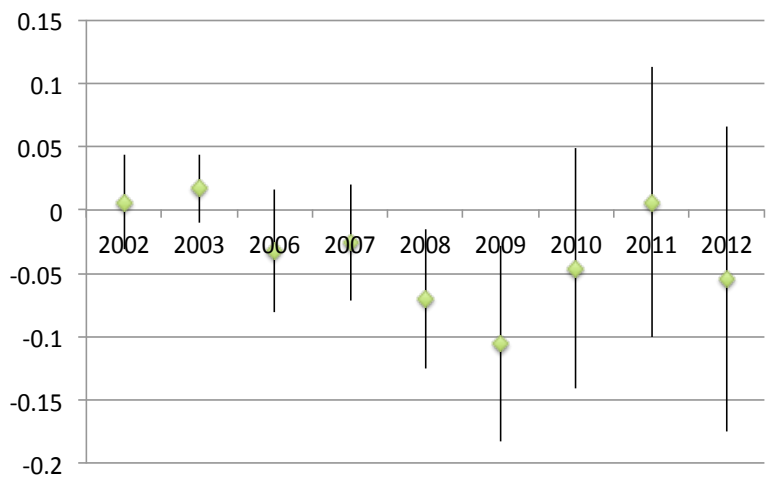

(d) Current

Figure 1: $\beta_{s(t)}$ for 4 quarter ahead transition probability from Newly Delinquent. Bars denote 95\% confidence intervals. Source: Authors' calculation based on Federal Reserve Bank of New York's Consumer Credit Panel/Equifax Data.

$60 \log$ points between 2005 and 2006-2008, and rises to 100 log points in 2011 and 2012, after abating somewhat during 2009 and 2010. Moreover, after controlling for economic controls and district effect, there appears to be no trend in the transition into bankruptcy after a new insolvency in the years prior to the reform. All the $\beta_{s(t)}$ coefficients are significant at least at the $5 \%$ level. The top right panel displays the transition from a new delinquency to insolvency, without foreclosure. In this case, there is a sharp and persistent rise in the transition to insolvency post reform, averaging approximately 20 log points. The bottom left panel displays the transition from a new delinquency to foreclosure (without bankruptcy), which rises by 80-100 log points post reform. Finally, the bottom right panel displays the transition probability from a new delinquency to Current. The probability declines by 5-15 log points post reform, suggesting that the decline in bankruptcy is not matched by a greater ability of newly delinquent individuals to repay their debt and return to being current. 
A stable $80 \%$ of newly insolvent households show a delinquency 1 quarter prior a new insolvency, as shown in table 1. Since individuals who eventually become bankrupt mostly transition to insolvency first, we also examine the transition probabilities from a new insolvency to Chapter 7 bankruptcy and foreclosure.

Table 1: Fraction of Newly Insolvents with Delinquency

\begin{tabular}{lllll}
\hline 6 qtrs before & 4 qtrs before & 2 qtrs before & 1 qtr before & At new insolvency \\
\hline $9.5 \%$ & $13.7 \%$ & $24.9 \%$ & $80.0 \%$ & $32.9 \%$ \\
\hline
\end{tabular}

1999-2012 averages. Source: Authors' calculation based on Federal Reserve Bank of New York's Consumer Credit Panel/Equifax Data.

Figure 2 displays the estimates for the transition into Ch. 7 bankruptcy and foreclosure. The transition into Ch. 7 bankruptcy (left panel) drops by 20 to 60 log points relative to the pre-reform average in this case, with the drop maximized in 2006-2008 and 2011-12. The right panel displays the transitions into foreclosure, which rises by approximately $40 \log$ points in the post reform period.
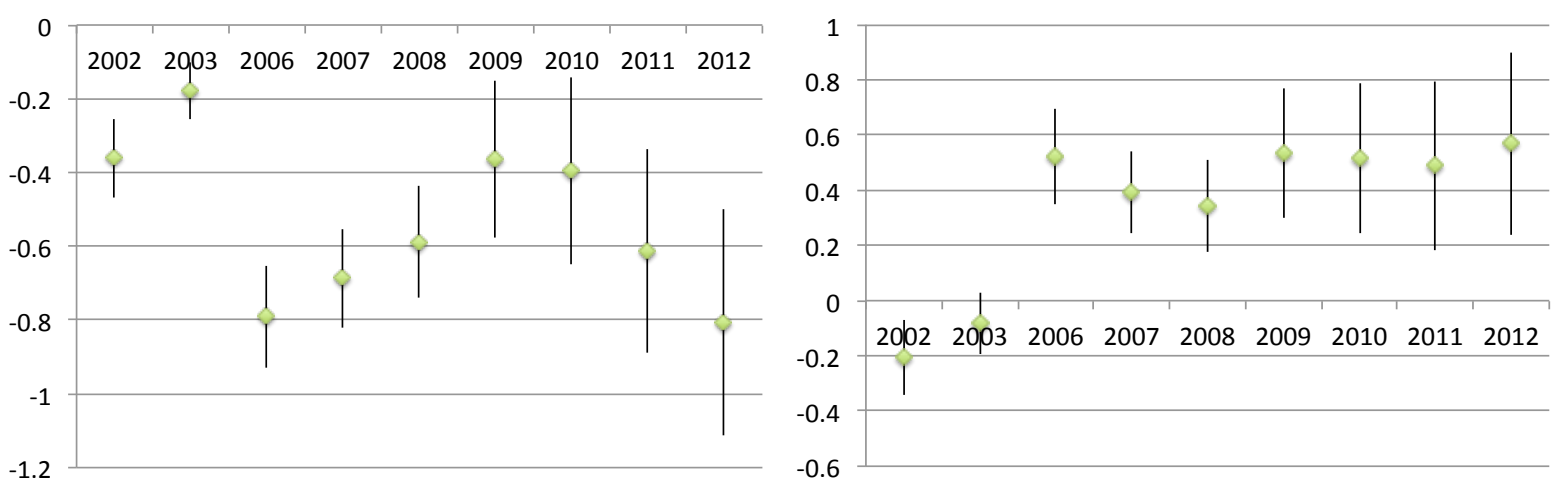

Figure 2: $\beta_{s(t)}$ for 4 quarter ahead transition probability from Newly Insolvent to Ch. 7 bankruptcy (left panel) and foreclosure (right panel). Bars denote 95\% confidence intervals. Source: Authors' calculation based on Federal Reserve Bank of New York's Consumer Credit Panel/Equifax Data.

The link between bankruptcy filing, real estate debt and foreclosure has been extensively discussed in the literature 15 This link can arise via several mechanisms. First, a bankruptcy

\footnotetext{
${ }^{15}$ Indeed, Fay, Hurst, and White (2002) argue that the financial benefit of filing for bankruptcy is intrinsically linked to real estate net worth, via the homestead exemption and other factors. See also Li (2009), Carroll and Li (2011), Morgan and Strain (2007), White and Zhu (2008), and Morgan, Iverson, and Botsch (2012).
} 
filing, both for Chapter 7 and Chapter 13, will stay a pending foreclosure procedure or the beginning of such procedure. In addition to this mechanical effect, individuals who file for bankruptcy may be able to renegotiate the terms of their mortgage loans, and thus repair a home debt delinquency, preventing foreclosure, or be able to cure an existing foreclosure. Finally, especially for Chapter 7 filers who are below their state's homestead exemption levels, the ability to discharge their unsecured debt may prevent any delinquencies on the home debt. On the other hand, the inability to file for bankruptcy may make foreclosure more appealing, as it enables individuals to discharge-at the cost of loosing their home-their home debt, which may enable them to remain current on their unsecured and other debt.16 In Section 5.5, we give evidence of a more direct link between the decline of the transition into Chapter 7 bankruptcy and the rise in foreclosure at the district level, that strongly suggests that the decline in foreclosure post-BAPCPA is associated with the resulting decline in bankruptcy.

Finally, we consider transitions into Chapter 13 bankruptcy filings from both a new delinquency and a new insolvency. The results are displayed in figure 3 . As can be seen from the figure, the transition to Chapter 13 bankruptcy declines from both a new delinquency (left panel) and a new insolvency (right panel), but the drop associated with the reform is much smaller than for Chapter 7 bankruptcy. From a new delinquency, there is an approximately 18 log point drop from 2004, while from a new insolvency, the drop from 2004 is approximately 25 log points in 2006-2007 and 35 log points 2012. In both cases, the transition into Chapter 13 bankruptcy rises by about $10 \log$ points between 2008 and 2009 .

The fact that transitions into Chapter 13 bankruptcy drops a lot less than the transition into Chapter 7 bankruptcy is consistent with the intent of BAPCPA, which imposed meanstesting and other requirements on Chapter 7 bankruptcy but left Chapter 13 bankruptcy mostly unaltered. The drop in Chapter 13 filings may be due to the fact that attorney fees for this procedure also rose (see Lupica (2012)).

For the rest of the analysis, we will focus on Chapter 7 bankruptcy for two reasons. First, Chapter 7 bankruptcy is the form of bankruptcy that offers the most effective form of debt relief, when the bankruptcy is discharged, and comprises the largest fraction of bankruptcy procedures, both pre-and post reform. As shown in Norberg and Velkey (2007) and Eraslan et al. (2014), only 33\% of all Chapter 13 bankruptcies are discharged, which corresponds to the fraction of filers that successfully complete the court mandated repayment plan.

\footnotetext{
${ }^{16}$ Our findings that transitions into foreclosure rise in response to the bankruptcy reform could be driven by any one of these mechanisms, and we plan to explore the empirical importance of these alternative forces in future work.
} 

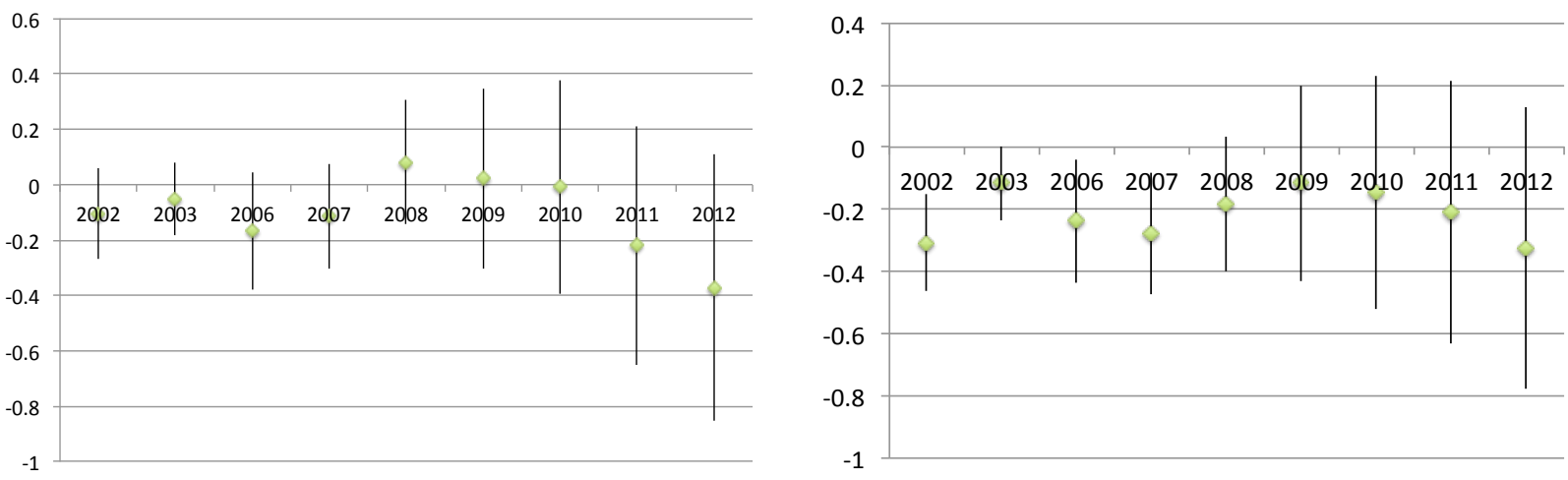

Figure 3: $\beta_{s(t)}$ for 4 quarter ahead transition probability from Newly Delinquent (left panel) and Newly Insolvent (right panel) to Chapter 13 bankruptcy filings. Bars denote 95\% confidence intervals. Source: Authors' calculation based on Federal Reserve Bank of New York's Consumer Credit Panel/Equifax Data.

Moreover, 30-33\% of debtors who have excited bankruptcy through discharge or dismissal filed again at least once, and even for those who emerged successfully from their cases through discharge, the refiling rate exceeds 20 percent. These values are extremely high considering that since the mid-1990s the unconditional bankruptcy filing rate for households in general is less than 1.5 percent in the U.S. Jagtiani and Li (2014) also find that Chapter 13 filers are much less likely to receive new credit cards than Chapter 7 filers even after controlling for borrower characteristics and local economic environment, consistent with Chapter 13 bankruptcy providing less of a fresh start in credit markets than Chapter $7{ }^{17}$ Second, Chapter 13 fees, including attorney fees, can be included in the repayment plan, and need not be presented upfront. The fact that Chapter 13 filers can borrow to pay for the bankruptcy procedure implies that liquidity constraints should not play a role for the response to Chapter 13 bankruptcy to the reform. In Section 5.3, we show that there is no link between the change in Chapter 13 attorney fees and the decline in Chapter 13 filings across districts, which we take as evidence supporting our hypothesis that the reduction of bankruptcy filings following BAPCPA was due to liquidity constraints.

\subsection{Transitions by Income}

One plausible explanation for the pre- and post-reform behavior is that the large rise in filing cost associated with the reform made it too expensive for certain individuals to file.

\footnotetext{
17 Jagtiani and Li (2014) find that Chapter 13 filers end up with a slightly larger credit limit amount than Chapter 7 filers overall, because they are able to maintain more of their old credit from before bankruptcy filing
} 
Moreover, these individuals, if indeed liquidity constrained, would likely end up in insolvency, rather than paying off their debts and becoming current. This is consistent with Gross, Notowidigdo, and Wang (2012), who find that bankruptcy filings rise for individuals who receive tax rebates. The Equifax data does not provide individual income. However, for 2009, we have access to payroll data, linked to Equifax, from a large income verification firm. We use these data in conjunction to the Survey of Consumer Finances (SCF) to impute labor income to individuals in our Equifax sample. The details of our imputation method are discussed in Appendix B.

In summary, our method is based on using the SCF to estimate an individual's income quartile, as a function of her debt holdings and age. Debt categories included are unsecured, auto, home, and student debt, where for each category, we index an individual's decile in the holdings of a particular debt category. This approach is robust to changes over time in the relation between debt levels and income levels. We estimate this relation for every year in our sample in which the SCF is available. We use the coefficients for the last available SCF year to determine an individual's income ranking by quarter until a new SCF survey becomes available. For 2009, we verify the accuracy of our imputation approach in the sample of individuals for which we have income data. We find that our imputation is highly successful at predicting whether individuals are in the first or fourth income quartile, and moderately successful at predicting whether individuals in the second and third quartile.

We estimate regression (1) for individuals below and above the median imputed income in each district and compare the estimates in figure 4. The estimates indicate that the effects of the reform are more pronounced for individuals below the median of the imputed income distribution. The left panel of figure 4 displays the estimates for the transition from new insolvency to bankruptcy. The drop in the transition into bankruptcy is deeper and more persistent for individuals below the median of the income distribution. The transition from a new insolvency to bankruptcy filing drops by $90 \log$ points for individuals below the median of the income distribution between 2004 and 2006, while it only drops by 50 log points for individuals above the median. The transition into bankruptcy rises for individuals below the median income during the 2007-09 recession, but it is still 20 log points lower than in 2004. It drops again for this group to $-80 \log$ points relative to 2004 by the end of our sample. For individuals above the median of imputed income, the bankruptcy settles to approximately 40 $\log$ points lower than in 2004 by 2008 . The difference between the transition from insolvency to bankruptcy for individuals below and above the median of imputed income is significant at least at the $10 \%$ level for most years, and significantly different at the $5 \%$ level in 2006-2009 and in 2011-2012. 
The right panel displays the estimates for the transition from a new insolvency to foreclosure. Here, we see a sizable and persistent rise for individuals below the median of the inputed income distribution, as well as for those above the median between 2004 and 2009 of approximately $50 \log$ points. After 2009, the transition into foreclosure continues to rise for individuals below the median of the imputed income distribution, ending 65 log points higher than in 2004 in 2012. For individuals above the median, the transition into foreclosure settles to approximately $35 \mathrm{log}$ points higher than in 2004.18 Taken together, these results suggest that the effects of the reform were stronger for individuals at the bottom of the income distribution.
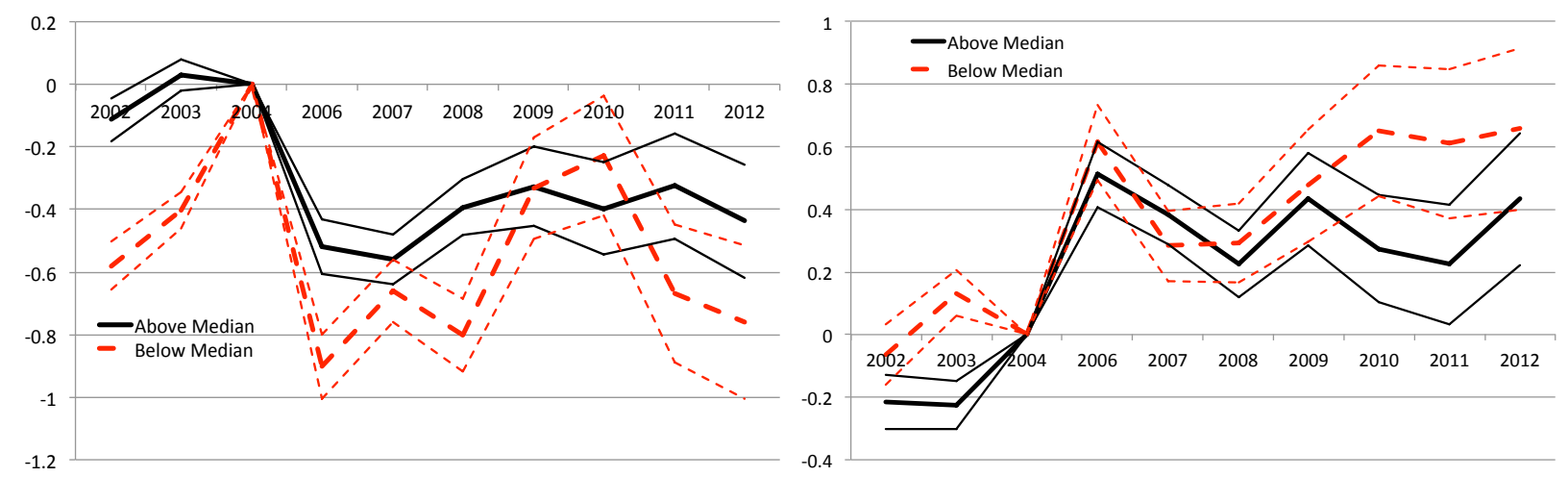

Figure 4: $\beta_{s(t)}$ for 4 quarter ahead transition probability from Newly Insolvent to Bankrupt (left panel) and from Newly Insolvent to Foreclosure (right panel) for individuals below and above the median of imputed income. Source: Authors' calculation based on Federal Reserve Bank of New York's Consumer Credit Panel/Equifax Data.

\section{Variation by District}

The introduction of the BAPCPA and the resulting increase in the filing requirements resulted in a significant increase in the filing costs for households (attorney fees, filing fee and debtor education expenses). Attorney fees, comprising approximately $75 \%$ of total direct access costs (both pre- and post-reform), are the biggest component of filing costs. Based on a comprehensive study of filing fees, Lupica (2012) reports an average increase in attorney fees of $37 \%$ for Chapter 7 filers. Behind these average increases, there is significant district-level variation: for example, for Chapter 7 filers, the cost changes vary from an increase of $122 \%$

\footnotetext{
${ }^{18}$ The relatively small difference in the transition from insolvency to foreclosure between individuals below and above the median of the imputed income distribution may be due to the fact that homeownership is lower for individuals with low income. See Appendix B for details.
} 
(Southern District of Georgia) to a drop of $28 \%$ (Southern District of Florida). In this section, we take attorney fees as a proxy for bankruptcy costs and exploit their variation across court districts in order to provide further evidence of the effects of the law on bankruptcy decisions, and specifically on the role of liquidity constraints in shaping the response to the reform.

We proxy the change in monetary costs associated with bankruptcy filing with the change in attorney fees for no asset cases, which account for around $90 \%$ of all bankruptcy filings. Table 2 presents descriptive statistics on the distribution of costs and cost changes. These costs exhibit a large cross-district variation both prior and after the bankruptcy reform. The prior range was $\$ 356$ (Tennessee Middle) to $\$ 1920$ (Florida Southern), while the post range is $\$ 543$ (Illinois Central) to $\$ 1530$ (Arizona). As argued in Lupica (2012), even controlling for state characteristics and filers' characteristics, BAPCPA had a significant effect on attorney fees changes across districts. The district average attorney fee pre-reform was $\$ 700$ and went up to $\$ 1000$ post-reform.

Table 2: Attorney fees: Chapter 7.

\begin{tabular}{llll}
\hline & Pre-reform & Post-reform & Log Difference \\
\hline Mean & $\$ 697$ & $\$ 975$ & $35 \%$ \\
90th percentile & $\$ 907$ & $\$ 1293$ & $61 \%$ \\
75th percentile & $\$ 786$ & $\$ 1123$ & $50 \%$ \\
Median & $\$ 663$ & $\$ 986$ & $33 \%$ \\
25th percentile & $\$ 589$ & $\$ 810$ & $22 \%$ \\
10th percentile & $\$ 473$ & $\$ 686$ & $17 \%$ \\
\hline
\end{tabular}

Figure 5 presents the pre- and post- reform levels of attorney fees for Ch. 7 bankruptcy by district, as well as the percentage change in these costs associated with the reform.

High Ch. 7 attorney fees are concentrated in the North and South East, the Gulf districts, and in California and New Mexico. Most of these districts also exhibit high attorney fees post-reform. The biggest percentage increases in attorney fees occur for some of the districts with the lowest pre-reform fees, however, the ranking of districts by Ch. 7 attorney fees is stable pre- and post-reform. The correlation between the pre- and post-reform ranking of these fees is $75 \%$. Tables 3 and 4 present descriptive statistics for the bankruptcy rate by district, pre- and post-reform, for filings and discharged cases. Figure 6 provides a visualization.

Our analysis proceeds in two steps. We first repeat our transitions analysis, grouping 
Pre-BAPCPA Bankruptcy Filing Costs

by United States Court District

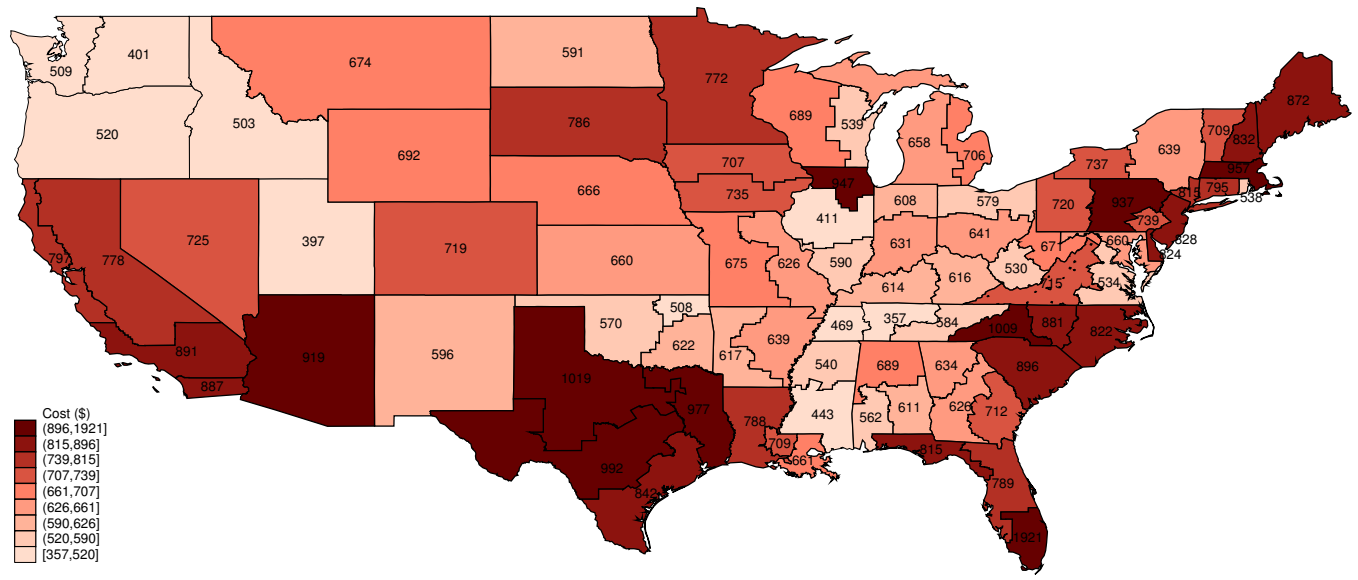

Post-BAPCPA Bankruptcy Filing Costs

by United States Court District

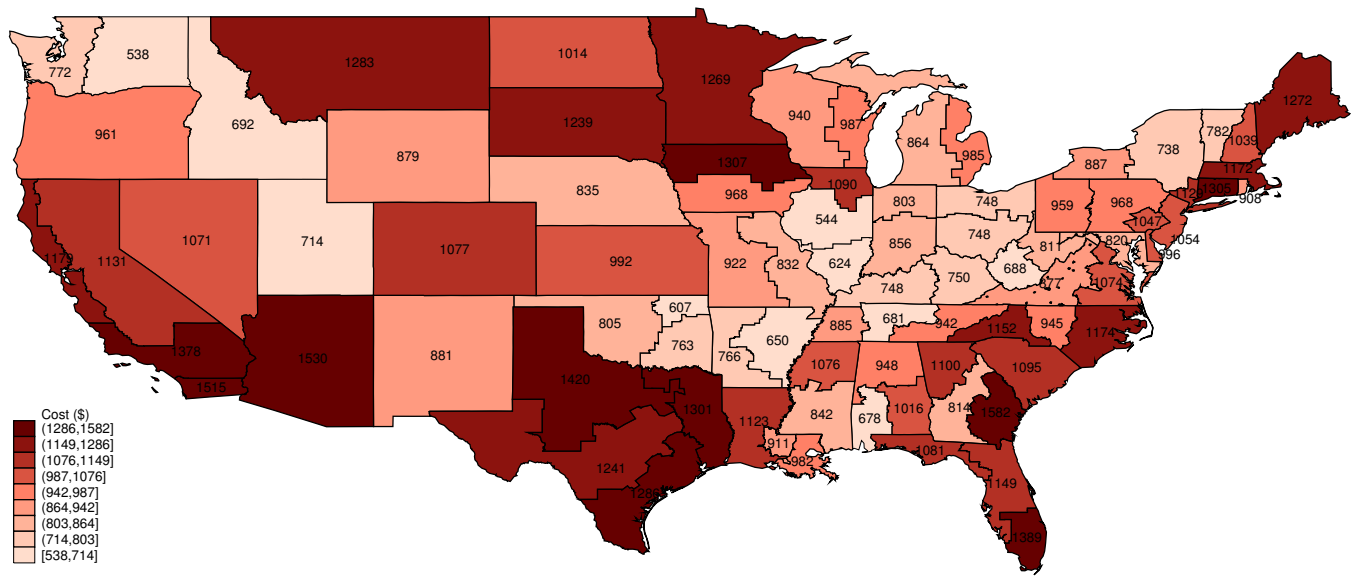

Percent Change in Bankruptcy Filing Costs for Households by United States Court District

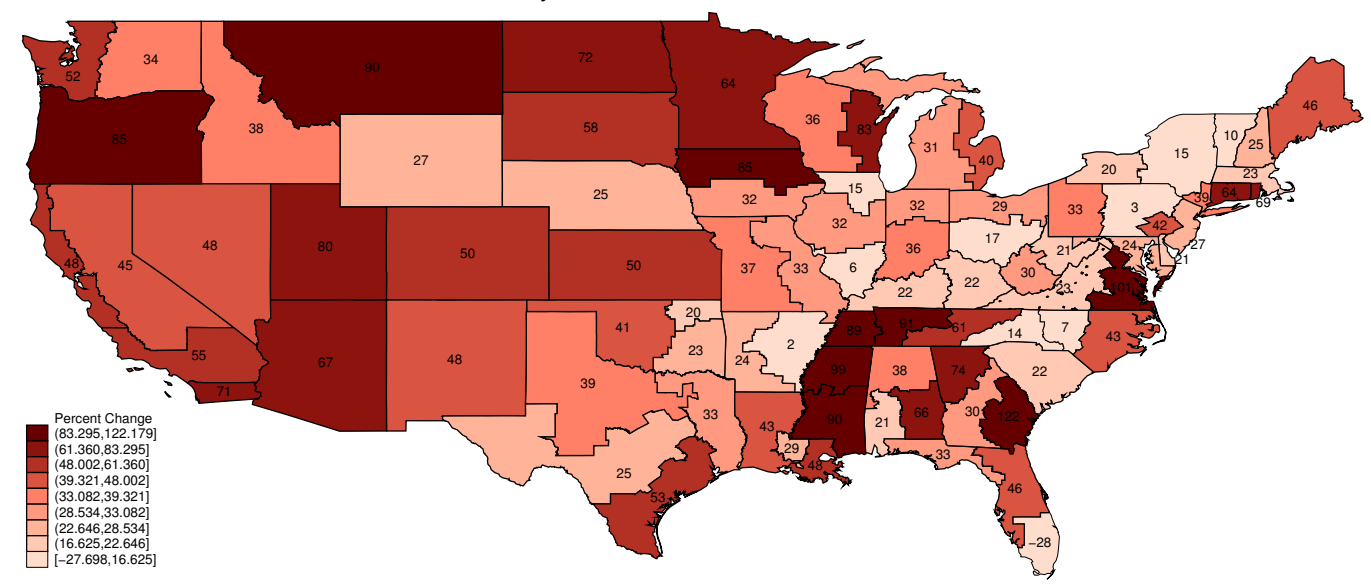

Figure 5: Attorney fees for Ch. 7 bankruptcy by district, pre- and post- reform, and percentage change associated with the reform. 
Table 3: Quarterly Chapter 7 bankruptcy rates: Filings.

\begin{tabular}{llll}
\hline & Pre-reform & Post-reform & Log Difference \\
\hline Mean & 1.80 & 1.14 & $-52 \%$ \\
90th percentile & 2.77 & 1.94 & $-11 \%$ \\
75th percentile & 2.19 & 1.48 & $-33 \%$ \\
Median & 1.70 & 1.04 & $-52 \%$ \\
25th percentile & 1.23 & 0.68 & $-71 \%$ \\
10th percentile & 0.94 & 0.47 & $-85 \%$ \\
\hline
\end{tabular}

Source: Authors' calculation based on Federal Reserve Bank of New York's Consumer Credit Panel/Equifax Data.

Table 4: Quarterly Chapter 7 bankruptcy rates: Discharged bankruptcy.

\begin{tabular}{llll}
\hline & Pre-reform & Post-reform & Log Difference \\
\hline Mean & 1.74 & 1.16 & $-37 \%$ \\
90th percentile & 2.96 & 2.00 & $1 \%$ \\
75th percentile & 2.17 & 1.51 & $-19 \%$ \\
Median & 1.53 & 1.03 & $-37 \%$ \\
25th percentile & 1.04 & 0.68 & $-54 \%$ \\
10th percentile & 0.68 & 0.46 & $-75 \%$ \\
\hline
\end{tabular}

Source: Authors' calculation based on Federal Reserve Bank of New York's Consumer Credit Panel/Equifax Data.

districts by their cost change, and comparing estimated transitions across districts with high and low changes in attorney fees associated with the reform. The second step consists in running a difference-in-difference exercise to obtain a quantitative assessment of the effect of the reform on bankruptcy, insolvency and foreclosure, taking into account variation in other variables that potentially influence these outcomes, such as economic conditions at the district level, or regulatory characteristics at the state level.

\subsection{Transitions by District}

We use the attorney fees changes for Chapter 7 bankruptcy filings by court district, reported in Lupica (2012), and then group districts into top-30\% ('high increase') and bottom-30\% 
('low increase') when ranked by filing cost percentage change ${ }^{19}$ We then compute the transition matrices, as in Section 3, separately for the high-increase and low-increase districts.

Our main findings are reported in figures 7 and 8, where the solid (black) line displays the estimated time effects from specification (1) transition probabilities for high cost change districts, and the dashed (red) line reports this average for low cost change districts.

Figure 7 displays the time effects for the transition probability from a delinquency to insolvent. While there is virtually no time variation for the low cost change district, there is a sharp rise in the transition into insolvency for high cost change district starting with the reform. The change settles at 40 log points in 2008.

The transition probability into bankruptcy from newly insolvent, displayed in figure 8 (left panel), drops more and more persistently in high cost change districts, consistent with the notion that the cost increase is the mechanism through which the reform affects the transitions into bankruptcy and severe delinquency. Finally, the transition probability from a new insolvency to foreclosure (figure 8, right panel) rises more than twice as much in high cost change districts relative to low cost change districts.

Summarizing, the cross-district analysis confirms our hypothesis that the increase in filing costs has significant implications for household bankruptcy and delinquency behavior. Our findings are consistent with the notion that higher increase in costs prevents a larger fraction of financially distressed individuals from filing for bankruptcy protection, pushing them into insolvency and foreclosure. Given evidence in Lupica (2012) that the cost increases are independent of business cycle or aggregate filing behavior, we view our findings as suggestive of direct effects of the law on these outcomes. In the next section, we provide further evidence by using a regression approach, where we control for business cycle and recession effects on the district level, and exploit the cross-district variation in filing cost.

\footnotetext{
${ }^{19}$ We focus here on Chapter 7, which is the dominant chapter of choice for US households - roughly $70 \%$ of observed filings are Chapter 7 filings. This chapter is also more suitable for filers with low assets, which are more likely to be cash-strapped, increasing the potential impact of filing costs changes.
} 
Pre-BAPCPA Chapter 7 Bankruptcy Filing Rates

by United States Court District

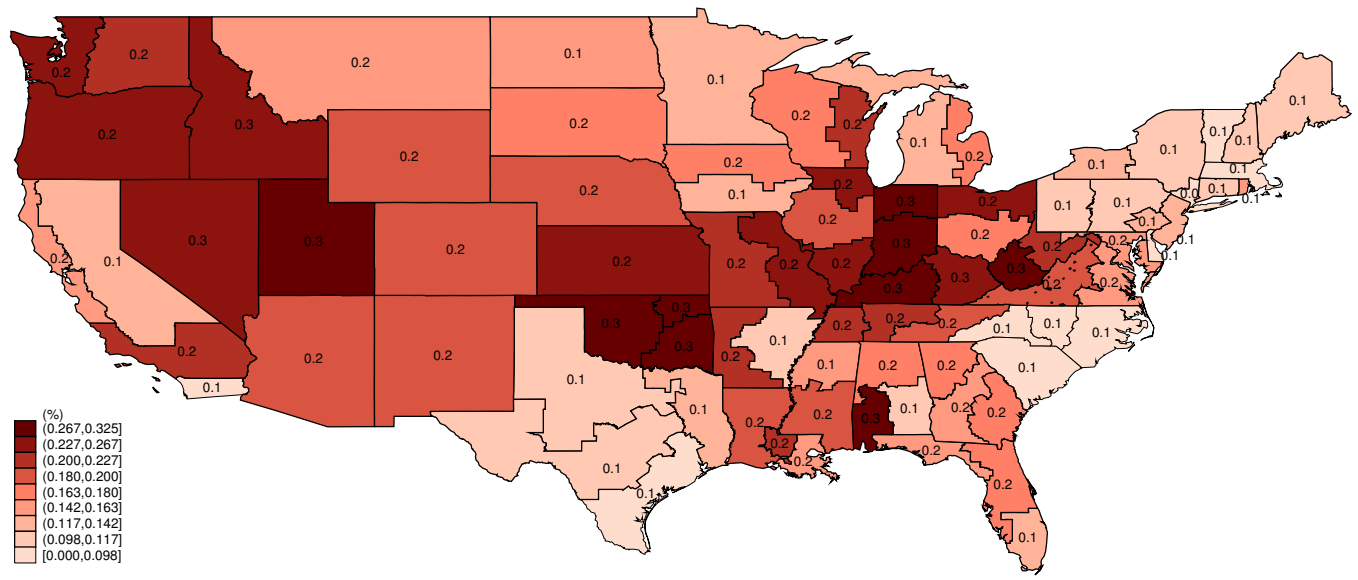

Post-BAPCPA Chapter 7 Bankruptcy Filing Rates

by United States Court District

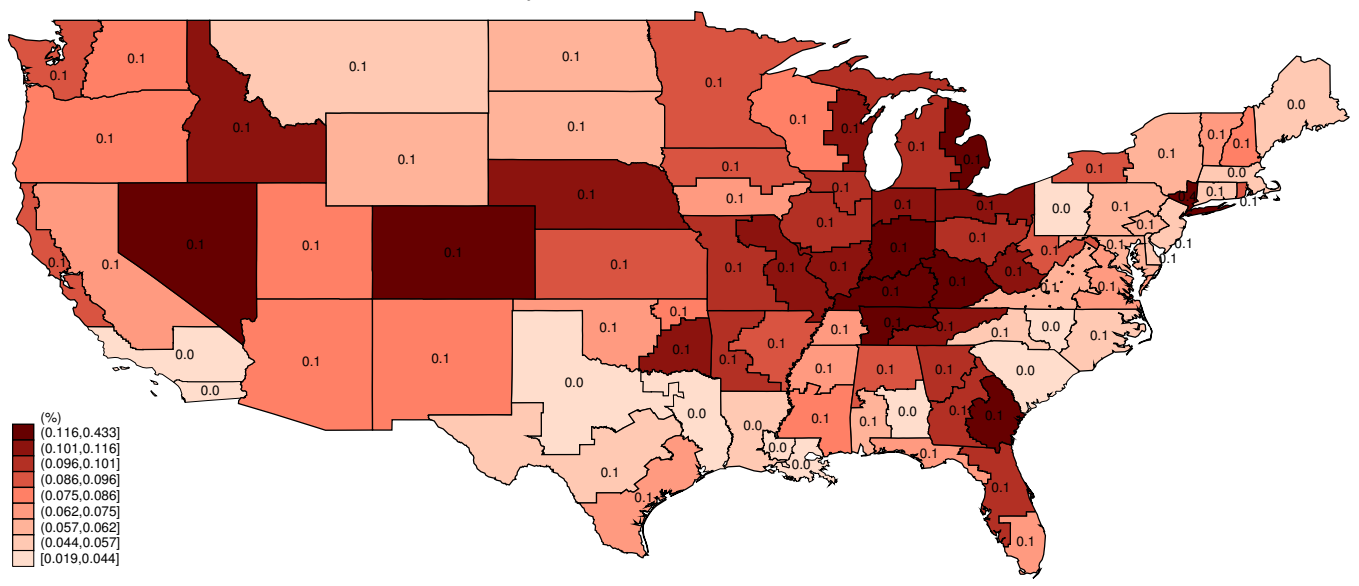

Percent Decrease in Chapter 7 Bankruptcy Filing Rates

by United States Court District

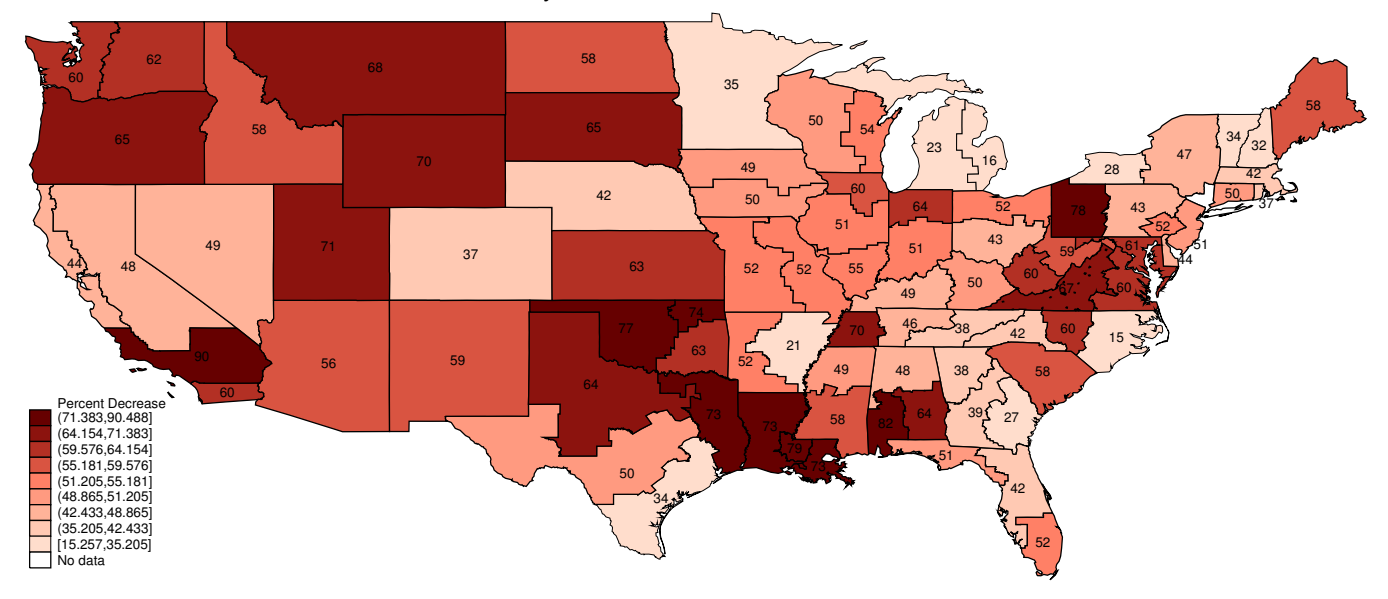

Figure 6: Chapter 7 bankruptcy by district, pre- and post- reform, and mean percentage drop post-reform. Source: Authors' calculation based on Federal Reserve Bank of New York's Consumer Credit Panel/Equifax Data. 


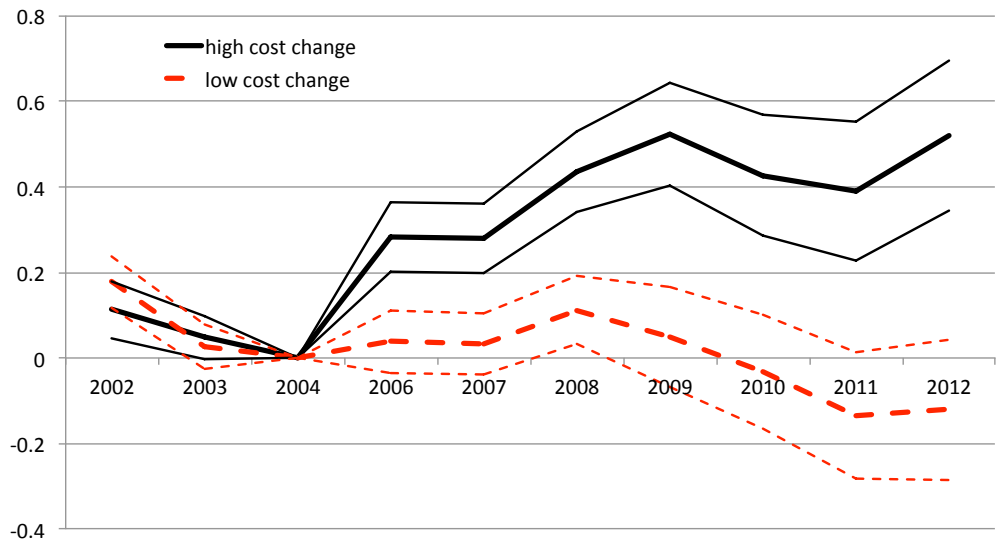

Figure 7: $\beta_{s(t)}$ for 4 quarter ahead transition probability from Newly Delinquent to Insolvent (without foreclosure) for districts in the top 30\% (high cost change) and bottom 30\% (low cost change) of the cost change distribution. Source: Authors' calculation based on Federal Reserve Bank of New York's Consumer Credit Panel/Equifax Data.

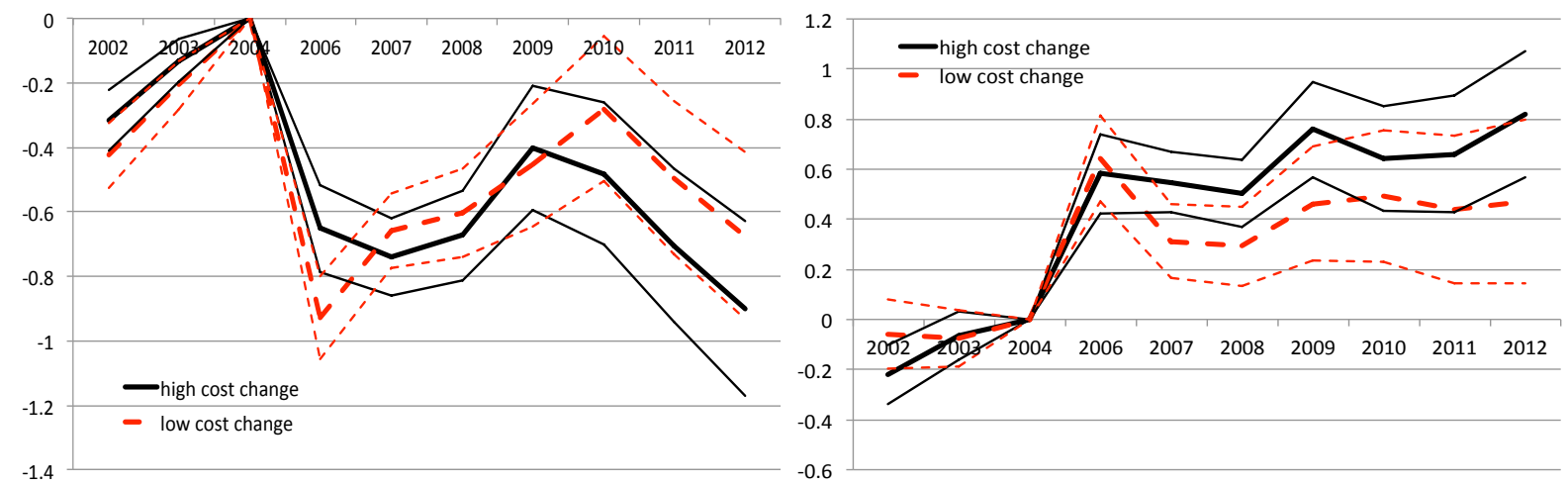

Figure 8: $\beta_{s(t)}$ for 4 quarter ahead transition probability from Newly Insolvent to Ch. 7 bankruptcy (left panel) and foreclosure (right panel) for districts in the top 30\% (high cost change) and bottom 30\% (low cost change) of the cost change distribution. Source: Authors' calculation based on Federal Reserve Bank of New York's Consumer Credit Panel/Equifax Data. 


\section{$5 \quad$ Regression analysis}

The purpose of this section is to assess the relation between the costs of filing for bankruptcy and bankruptcy decisions. To this end, we exploit the sizable cross-district variation in lawyer fees associated with filing for bankruptcy as well as the cross-district variation in the change in these costs following BAPCPA. Using a difference-in-difference approach, we establish that districts with higher change in filing costs exhibited a larger decline in bankruptcy rates, controlling for other district characteristics and district business cycle effects.

We adopt the following difference-in-difference specification:

$$
y_{i t}=\alpha+\beta c_{i, t}+\psi I_{t}^{p o s t}+\phi X_{i t}+\epsilon_{i t}
$$

where $y_{i t}$ is the log of the outcome of interest, $c_{i}$ the log of the bankruptcy filing cost, and $X_{i t}$ is a vector of district level controls, with $i$ denoting districts and $t$ quarters.

Our main variable of interest is the transition probability from a new insolvency to bankruptcy filing at the district level. The coefficient $\beta$ captures the effect of the log change in the cost post-reform on the log of the transition from new insolvency to bankruptcy post-reform. To see this, we take the first difference, which corresponds to time:

$$
y_{i t^{\prime}}-y_{i t}=\psi+\beta \Delta c_{i}+\phi\left(X_{i t^{\prime}}-X_{i t}\right) \text {, }
$$

where $t$ and $t^{\prime}$ denotes quarter pre-and post reform, and $\Delta c_{i}$ is the log change in the filing cost associated with the reform. Then, we take a second difference across districts:

$$
\Delta y_{i t}-\Delta y_{j t}=\beta\left(\Delta c_{i}-\Delta c_{j}\right)+\phi\left(\Delta X_{i t}-\Delta X_{j t}\right)
$$

where $\Delta x_{i t}$ denotes the change over time of a variable $x$ in district $i$.

This specification assumes that the sensitivity of the transition into bankruptcy to the cost level and to the economic controls is constant pre- and post- reform. We also consider less restrictive formulations, in which we relax these assumptions in turn. The results are displayed in Table 5. We include the same economic controls and state level regulatory controls in all formulations. The economic controls include logs of personal income, the un-

employment rate, house price index and their 4 quarter changes. The state level regulatory controls include the wage garnishment limit, the homestead exemption level and indicators for judicial foreclosure states and for recourse states. These are intended capture the im- 
pact of state level regulation on the incentives to go bankrupt ${ }^{20}$ For example, in a state with higher wage garnishment limit, delaying bankruptcy is more costly. Conversely, higher homestead exemptions may render bankruptcy more attractive for home owners. Since these variables are time invariant, we do not include district fixed effects for this specification.

Column (1) corresponds to the baseline specification. Based on the estimated value of the coefficient on the filing cost, the median rise in lawyer fees post-reform $(52 \%)$ reduces the transition from a new insolvency into bankruptcy by 18 log points, in addition to the $80 \log$ point decline of the transition into bankruptcy estimated by the coefficient on the reform dummy ${ }^{21}$ The transition into bankruptcy is positively related to the change in unemployment in the 4 quarters prior, and negatively related to the change in the house price index 4 quarters prior.

Column (2) reports a version of the baseline specification in which the sensitivity of the transition into bankruptcy is allowed to differ pre- and post-reform. Instead of the cost level, we include two regressors, the cost level pre-reform interacted with the pre-reform dummy, and the cost level post-reform interacted with the post-reform dummy. Notably, only the coefficient on the post-reform is consistently negative, suggesting that moving from the 25 th to the 75 th percentile of the filing cost post-reform reduces the transition into bankruptcy by $17 \log$ points.

Columns (3) and (4) report estimates for the baseline specification estimated only on pre- and post-reform data, respectively. This allows us to detect a change of the sensitivity to the economic controls of the transition into bankruptcy. Both in the pre- and post-reform period, we find a sizable and significant negative relation between the filing costs and the transition into bankruptcy. Moving from the 25th to the 75 th percentile of the filing cost distribution reduces the transition into bankruptcy by 13 log points in the pre- and $14.5 \log$ points in the post-reform periods. However, the sensitivity of the transition into bankruptcy to the economic controls varies noticeably pre- and post-reform. None of the controls are significant in the pre-reform period, while post-reform, the transition into bankruptcy is significantly positively related to the 4 quarter change in income and unemployment, and significantly negatively related to the 4 quarter change in house prices.

\footnotetext{
${ }^{20}$ Hynes, Dawsey, and Ausubel (2009) show that the regulation of debt collection at the state level can influence the decision to go bankrupt.

${ }^{21}$ We exclude from the sample the period 2005.Q1 to 2006.Q1 to exclude the effects of reform anticipation that simply shift the timing of bankruptcies.
} 
Table 5: Transition from New Insolvency to Bankruptcy: OLS Estimates

\begin{tabular}{lllll}
\hline & $(1)$ & $(2)$ & $(3)$ & $(4)$ \\
\hline Filing Cost & $-0.34(1.96)$ & & & \\
Filing Cost Pre & & $-0.13(0.72)$ & $-0.49(2.62)$ & $-0.42(2.52)$ \\
Filing Cost Post & & $-0.52(3.06)$ & & \\
Reform Dummy & $-0.80(6.49)$ & $1.83(1.70)$ & & \\
Income & $0.32(1.18)$ & $-0.32(1.2)$ & $0.00(0.02)$ & $0.46(1.71)$ \\
$\Delta$ Income & $0.59(1.61)$ & $0.60(1.82)$ & $0.12(0.23)$ & $1.56(4.06)$ \\
Unemployment & $0.17(1.03)$ & $0.16(0.97)$ & $0.12(0.69)$ & $0.06(0.31)$ \\
$\Delta$ Unemployment & $0.33(3.27)$ & $0.33(3.39)$ & $-0.26(1.65)$ & $0.46(4.11)$ \\
House Price Index & $-0.10(0.36)$ & $-0.11(0.39)$ & $-0.08(0.23)$ & $-0.31(1.00)$ \\
$\Delta$ HPI & $-1.01(3.82)$ & $-1.10(4.32)$ & $0.79(0.76)$ & $-1.55(4.69)$ \\
Regulation & Yes & Yes & Yes & Yes \\
Adjusted $R^{2}$ & 0.42 & 0.42 & 0.18 & 0.33 \\
$\mathrm{~N}$ & 2327 & 2327 & 1815 & 1512 \\
\hline
\end{tabular}

All variables (except indicators) in logs. All observations are weighted by district level population. Standard errors are clustered at the district level. Absolute values of the t-statistics are reported in parentheses. We are dropping observations from 2005.Q1 to 2006.Q1 to exclude anticipation effects. Here $\Delta$ denotes the 4 quarter change from the current quarter. Source: Authors' calculation based on Federal Reserve Bank of New York's Consumer Credit Panel/Equifax Data.

\subsection{Exogeneity of the cost change}

One concern with using the filing fees as explanatory variables is that the change in fees associated with the reform may be jointly endogenous with the bankruptcy rate or its change. Table 6 examines the relation of the filing costs and their changes with prior economic indicators, state level regulation and prior bankruptcy, insolvency and foreclosure behaviors. Our results suggests that the filing costs and their changes do not display evidence of joint endogeneity. In particular, neither the cost post-reform or the cost change are related to prior bankruptcy, foreclosure or insolvency rates. In fact, the only variable in table 6 which seems to be statistically related to the cost change is the indicator for judicial foreclosure. Our conclusion is that we can reasonably assume that the joint endogeneity issues do not arise in our specification. However, for robustness, we also conduct an instrumental variable analysis in the next subsection. 


\subsection{Instrumental Variable Approach}

We instrument the cost change in two ways. First, we construct a new instrument for the change in fees that exploits the appointment process for bankruptcy judges. Second, we use the cost level pre-reform to instrument for the change.

In terms of the instrument that exploits the appointment process of bankruptcy judges, we posit that the change in fees associated with the reform is driven by the political preference of the bankruptcy judges in office in each district at the time of the implementation of reform. Bankruptcy judges are appointed by the Court of Appeals, in the Circuit to which each district belongs, to renewable 14 year terms. Therefore, we assume that the political affiliation of the bankruptcy judges will reflect the affiliation of the magistrates on the Court of Appeals at the year of first appointment of each bankruptcy judge. Magistrates on appellate courts also serve renewable 14 year terms and are appointed by the President of the United States. We therefore proxy the political affiliation of each magistrate on the Court of Appeals with the party of the President who appointed that magistrate. We then aggregate the preferences across sitting appellate magistrates to obtain a unique measure, corresponding to the fraction of magistrates appointed by Republican presidents, for each bankruptcy judge. Since each court district has several bankruptcy judges, to obtain a measure of political affiliation at the district level, we compute the weighted average of the political affiliation of the bankruptcy judges in the district, with weights given by their tenure in the bankruptcy court 22

As shown in Appendix C, the evolution over time of the political affiliation of the Court of Appeals in each circuit depends on the party of the sitting President. Moreover, our instrument is not correlated with local preferences at the district level, which could drive both the attorney fee change and bankruptcy outcomes via their influence on local culture or judicial norms. These properties speak to the exogeneity of the instrument. The instrument is also economically salient. We expect that the political preferences of the bankruptcy judges comprised in each court would matter in shaping their recommendation for reasonable lawyer fees, given that they understand that the structure of those fees affects filing patterns. As shown in Table 7, column (1), the first stage regressions suggest that the instrument (denoted with Judge Preference) is significantly negatively related to the cost change, though it is somewhat weak.

In terms of using the pre-reform cost to instrument the post-reform cost, the pre-reform cost is clearly exogenous relative to the bankruptcy behavior in the post reform period, and

\footnotetext{
${ }^{22} \mathrm{We}$ also experiment with unweighted averages. The results we will present are not sensitive to the aggregation scheme.
} 
it is significantly negatively related with the cost change, as shown in Table 7, column (2).

We estimate the version of specification (2) in table 5 that allows for different coefficients on the filing costs pre- and post-reform. The results are displayed in Table 7. Column (1) displays the estimates when the cost post-reform is instrumented by a variable obtained by summing the pre-reform cost and the first stage projection of the cost change associated with the reform. Column (2) displays estimates for a version in which the cost post-reform is instrumented with the cost pre-reform.

The increase of the filing cost post-reform is strongly negatively related to the bankruptcy filing rate in the post-reform period. Moving from the 25th to the 75th percentile of the post-reform cost distribution reduces the transition from a new insolvency to bankruptcy by $11 \log$ points for the specification in column (1), and by $21 \log$ points for the specification in column (2). Additionally, the transition into bankruptcy is significantly positively related to the change in unemployment, and significantly negatively related to the change home price index for both specifications. 
Table 6: Exogeneity of the filing costs and filing cost changes.

\begin{tabular}{|c|c|c|c|c|}
\hline \multicolumn{5}{|c|}{ Panel I: Economic Indicators } \\
\hline & Income & Unemployment & HPI & \\
\hline Filing Cost Post & $0.43(3.38)$ & $-0.02(0.18)$ & $0.64(2.93)$ & \\
\hline$R$ squared & 0.11 & 0 & 0.08 & \\
\hline Log Change & $-0.03(0.31)$ & $-0.04(0.53)$ & $-0.08(0.44)$ & \\
\hline$R$ squared & 0 & 0 & 0 & \\
\hline $\mathrm{N}$ & 89 & 89 & 85 & \\
\hline \multicolumn{5}{|c|}{ Panel II: Regulatory Variables } \\
\hline & Homestead & Garnishment & Recourse & Judicial \\
\hline Filing Cost Post & $0.04(2.64)$ & $0.0002(1.91)$ & $-017(2.96)$ & $-0.04(0.81)$ \\
\hline$R$ squared & 0.08 & 0.04 & 0.09 & 0.008 \\
\hline Log Change & $-0.005(0.42)$ & $-0.0002(2.40)$ & $-0.04(0.93)$ & $-0.12(3.30)$ \\
\hline$R$ squared & 0.002 & 0.06 & 0.01 & 0.11 \\
\hline $\mathrm{N}$ & 89 & 89 & 89 & 89 \\
\hline \multicolumn{5}{|c|}{ Panel III: Prior Behavior } \\
\hline & Bankruptcy & Foreclosure & Insolvency & \\
\hline Filing Cost Post & $-0.01(0.93)$ & $-0.05(0.76)$ & $-0.008(0.09)$ & \\
\hline$R$ squared & 0.01 & 0.007 & 0 & \\
\hline Log Change & $0.005(0.46)$ & $-0.003(0.06)$ & $-0.02(0.28)$ & \\
\hline$R$ squared & 0.002 & 0 & 0 & \\
\hline $\mathrm{N}$ & 89 & 89 & 89 & \\
\hline
\end{tabular}

Numbers in parentheses are the absolute values of t-statistics. Bankruptcy, Foreclosure and Insolvency are average pre-BAPCPA Chapter 7 filing rate, foreclosure rate and insolvency rate at the district level. Homestead and Garnishment are log homestead exemption and wage garnishment. Judicial and Recourse are indicators for judicial foreclosure state and recourse state. Income, Unemployment and HPI are district level pre-BAPCPA means of the logs of those variables. Source: Authors' calculation based on Federal Reserve Bank of New York's Consumer Credit Panel/Equifax Data. 
Table 7: Transition from New Insolvency to Bankruptcy: IV Estimates

\begin{tabular}{lcc}
\hline & $(1)$ & $(2)$ \\
\hline IV Filing Cost Post & $-0.33(2.07)$ & $-0.65(2.41)$ \\
Filing Cost Pre & $-0.13(0.62)$ & $-0.20(0.98)$ \\
Reform Dummy & $0.56(0.83)$ & $2.26(2.65)$ \\
Income & $0.28(1.00)$ & $0.31(1.11)$ \\
$\Delta$ Income & $0.41(1.11)$ & $0.56(1.68)$ \\
Unemployment & $0.19(1.08)$ & $0.20(1.19)$ \\
$\Delta$ Unemployment & $0.33(2.97)$ & $0.31(2.92)$ \\
House Price Index & $-0.13(0.44)$ & $-0.06(0.20)$ \\
$\Delta$ HPI & $-0.99(3.10)$ & $-1.13(4.00)$ \\
Regulation & Yes & Yes \\
Adjusted $R^{2}$ & 0.42 & 0.43 \\
N & 2266 & 2327 \\
\hline & First Stage Regressions \\
\hline Judge Preference & $-0.16(1.70)$ & \\
Filing Cost Pre & & $-0.35(5.07)$ \\
Regulation & Yes & No \\
F-stat & 4.67 & 25.74 \\
Weak Identification F & 2.9 & 89 \\
N & 85 & \\
\hline
\end{tabular}

All observations are weighted by district level population. Standard errors are clustered at the district level. Absolute values of the t-statistics are reported in parentheses. We are dropping observations from 2005.Q1 to 2006.Q1 to exclude anticipation effects. We use the Craig-DonaldWald F statistic to detect weak identification. $\Delta$ denotes 4 quarter changes. Source: Authors' calculation based on Federal Reserve Bank of New York's Consumer Credit Panel/Equifax Data. 


\subsection{Chapter 13 Bankruptcy}

We now characterize the response of Chapter 13 filings to BAPCPA. The reform increased bankruptcy filing costs for Chapter 13 bankrupts by $25 \%$ on average(Lupica (2012)). However, Chapter 13 legal fees can be included in the debt that enters the repayment plan: effectively Chapter 7 fees have to be paid up-front in their entirety, while Chapter 13 fees can be paid in installments. If our hypothesis that the effects on bankruptcy filings are a direct consequence of the increase in cost and the inability to pay it up-front is correct, we should see no statistical effects of Chapter 13 filing costs on filings. This is what we find in our data. Specifically, we estimate the specifications in Table 5 and 7 , where we use the log lawyer fees for Chapter 13 and log transitions from new insolvency to Chapter 13 filing. The results are presented in Table 8. There is no statistical relation between Chapter 13 filings and Chapter 13 lawyer fees, either before or after the reform. This results confirms the small effects visualized in figure 3. It is worth noting that these result still mean that in relative terms, the economy exhibited a shift from Chapter 7 to Chapter 13 bankruptcy, but that the relative effect is driven by Chapter 7 transitions dropping.

Table 8: Effects of the Reform: Chapter 13 Filings

\begin{tabular}{llllll}
\hline Specification & $(1)$ & $(2)$ & $(3)$ & $(4)$ & IV $(2)$ \\
\cline { 1 - 4 } Ch.13 Filing Cost & $-0.05(0.28)$ & & & \\
Ch.13 Filing Cost Pre & & $-0.004(0.02)$ & $0.02(0.08)$ & & $-0.01(0.05)$ \\
Ch.13 Filing Cost Post & & $-0.08(0.38)$ & & $-0.05(0.25)$ & $-0.21(0.53)$ \\
$R$ squared & 0.29 & 0.29 & 0.36 & 0.29 & 0.29 \\
$\mathrm{~N}$ & 1462 & 1462 & 462 & 1000 & 1462 \\
\hline
\end{tabular}

Only coefficients on the costs are reported. The regressions include all the controls reported in table 5. Footnotes from tables 5 and 7 apply. Source: Authors' calculation based on Federal Reserve Bank of New York's Consumer Credit Panel/Equifax Data.

\subsection{Regressions By Income}

To further explore the role of liquidity constraints, we estimate our main regressions for imputed income above and below national median. Specifically, we estimate equation (2) for individuals in these two categories separately. The goal of the exercise is to assess whether the effects of the change in bankruptcy filing costs estimated in the overall population are more pronounced in the lowest income group, which would give additional support to the hypothesis that the change in filing costs are driving the responses to the bankruptcy reform. 
Table 9 reports coefficients on costs for specifications (1)-(4) from table 5 and specification (2) from table 7. The estimates suggests that the effect of the bankruptcy filing cost is stronger for lower income individuals. For all specifications, including the instrumental variable regression, the coefficients are larger in absolute value for the lowest quartile relative to the rest of the population.

Table 9: Effects of the Reform: Income Above and Below Median.

\begin{tabular}{|c|c|c|c|c|c|}
\hline \multicolumn{6}{|c|}{ Below Median Income } \\
\hline Specification & (1) & $(2)$ & $(3)$ & $(4)$ & $\operatorname{IV}(2)$ \\
\hline Filing Cost & $-0.37(2.00)$ & & & & \\
\hline Filing Cost Pre & & $-0.31(1.43)$ & $-0.72(3.22)$ & & $-0.44(1.96)$ \\
\hline Filing Cost Post & & $-0.44(2.00)$ & & $-0.36(1.80)$ & $-0.81(2.82)$ \\
\hline$R$ squared & 0.32 & 0.32 & 0.26 & 0.25 & 0.33 \\
\hline $\mathrm{N}$ & 1587 & 1587 & 603 & 984 & 1587 \\
\hline \multicolumn{6}{|c|}{ Above Median Income } \\
\hline Specification & $(1)$ & $(2)$ & $(3)$ & $(4)$ & IV $(2)$ \\
\hline Filing Cost & $-0.27(1.67)$ & & & & \\
\hline Filing Cost Pre & & $-0.08(0.45)$ & $-0.39(2.23)$ & & $-0.14(0.76)$ \\
\hline Filing Cost Post & & $-0.43(2.71)$ & & $-0.32(2.03)$ & $-0.58(2.41)$ \\
\hline$R$ squared & 0.35 & 0.36 & 0.26 & 0.24 & 0.36 \\
\hline $\mathrm{N}$ & 2005 & 2005 & 707 & 1298 & 2005 \\
\hline
\end{tabular}

Only coefficients on the costs are reported. The regressions include all the controls reported in table 5. Footnotes from tables 5 and 7 apply. Source: Authors' calculation based on Federal Reserve Bank of New York's Consumer Credit Panel/Equifax Data. 


\subsection{Substitution from Bankruptcy}

Section 3 shows that the decline in the transition to bankruptcy associated with the reform was accompanied by a sizable rise in insolvency and foreclosure. In this section, we quantify the substitution effect using regression analysis. This allows us to control for district-specific and overall economic conditions to isolate the impact of the reform.

As before, we focus on the population of newly insolvent individuals, and compute the rate at which they transition into various states at a 4 and 8 quarter horizons. The states we are interested in are insolvency (without foreclosure), Ch. 7 and 13 bankruptcy (without foreclosure) and foreclosure. Mechanically, the decreased transition to bankruptcy documented earlier must be accompanied by increases in transitions into other possible outcomes. We document a substitution pattern from bankruptcy to insolvency, with a corresponding increase in the persistence of the insolvent state, and foreclosure. We find no effect on the transition into current from a new insolvency at a 4 quarter horizon, and a small effect at the 8 quarter horizon.

Our analysis aims to capture the effect of within-district persistent drop of flows to bankruptcy on flows to other states. To that end, we adopt a two step procedure. We first obtain the average change in flows to bankruptcy, insolvency, foreclosure and current, driven by the reform, controlling for economic factors. Formally, we estimate:

$$
y_{i t}=\sum_{i} \gamma_{i} I_{i t}^{p o s t}+\phi X_{i t}+I_{t}+D_{i}
$$

where $I_{i t}^{\text {post }}$ is a set of district-specific post-reform dummies, $D_{i}$ are district effects, $I_{t}$ are timeeffects, and $X_{i t}$ is a vector of district-level economic controls. $X_{i t}$ includes logs of income, unemployment rate and house price index, as well as 4-quarter changes in log income, log house price index and the log unemployment rate. The output of interest from this step is the set of district dummies $\gamma_{i}$, which capture the log change in average flows not explained by our other controls.

In the second step of our estimation procedure, we regress the district dummies for other outcome states, $\left\{\gamma_{i}\right\}$ estimated in the first stage, on the district dummies estimated for flows into Ch. 7 bankruptcy filings:

$$
\gamma_{i}=\alpha+\beta \gamma_{i}^{i n s \rightarrow b a n k 7}
$$

The estimated coefficient $\beta$ will capture the direction and statistical strength of the relation between the drop in flows to bankruptcy and the other flows of interest, after controlling for the impact of economic and regulatory controls on these flows. 
We report the estimates for flows from newly insolvent to insolvency the other states in table 10. At the 4 quarter horizon, the median estimated bankruptcy transition drop (66\%) increases the persistence of insolvency by 3.3\% (the median change is $1.1 \%$ ). Shifting from the 10th to the 90th percentile of the bankruptcy transition distribution (86 log points drop) results in an change of the increase of the persistence of insolvency by an additional $4.3 \%$. For the flows to foreclosure, the results are much more dramatic. At the 4-quarter horizon, the median drop in flows into bankruptcy results in a $34 \%$ percent increase in flows into foreclosure (compared to a median increase of these flows of $56 \%$ ). There is no evidence that the law had any effect on transitions to current in the short run (4 quarters), but it seems to have increased the flow into current at longer horizons-the median drop in bankruptcy transition increases the flows to current by $3 \%$.

Table 10: Evidence on the effects of the reform: Substitution from Bankruptcy.

\begin{tabular}{|c|c|c|}
\hline Horizon & $4 Q$ & $8 Q$ \\
\hline & \multicolumn{2}{|c|}{ Flow to Insolvency } \\
\hline Flow to Bankruptcy & $-0.05(1.89)$ & $-0.08(2.36)$ \\
\hline \multirow[t]{2}{*}{$R^{2}$} & 0.03 & 0.05 \\
\hline & \multicolumn{2}{|c|}{ Flow to Foreclosure } \\
\hline Flow to Bankruptcy & $-0.51(3.65)$ & $-0.54(4.14)$ \\
\hline \multirow[t]{2}{*}{$R^{2}$} & 0.13 & 0.17 \\
\hline & \multicolumn{2}{|c|}{ Flow to Current } \\
\hline Flow to Bankruptcy & $0.04(1.34)$ & $-0.05(2.00)$ \\
\hline \multirow[t]{2}{*}{$R^{2}$} & 0.01 & 0.04 \\
\hline & \multicolumn{2}{|c|}{ Flow to Chapter 13} \\
\hline Flow to Bankruptcy & $0.06(0.68)$ & $0.75(4.78)$ \\
\hline \multirow[t]{2}{*}{$R^{2}$} & n.a. & 0.21 \\
\hline & \multicolumn{2}{|c|}{ Flow to Foreclosure } \\
\hline Flow to Bankruptcy 7 & $-0.43(3.05)$ & $-0.54(4.31)$ \\
\hline Flow to Bankruptcy 13 & $-0.21(1.47)$ & $0.03(0.27)$ \\
\hline$R^{2}$ & 0.13 & 0.17 \\
\hline
\end{tabular}

The estimates are obtained using robust regression to control for the effects of outliers. Horizon denotes the horizon of the outcome variable-flows to bankruptcy are kept at the 4 quarter horizon. Source: Authors' calculations based on Federal Reserve Bank of New York's Consumer Credit Panel/Equifax Data. 
Interestingly, when we estimate the effects on flows to Chapter 13 bankruptcy, we find that for long horizons, flows into Chapter 7 and 13 are positively correlated (fourth panel in Table 10 at the 8 quarter horizon). It is then possible that the flows into foreclosure are driven by a drop in Chapter 13, not Chapter 7 decreases. In order to investigate that hypothesis, we estimate the second stage specification including both the Chapter 7 and the Chapter 13 estimated $\gamma_{i}$ at 4 and 8 quarters horizons. The results, reported in the last panel of table 10, indicate that the Chapter 7 flows are associated with statistically stronger response of the flows into other states. The flows to Chapter 13 are not statistically significant in that regression.

Substitution from initial state Current We also provide evidence on the flows conditional on individuals being initially Current, that is on time on all accounts with no bankruptcy or foreclosure for the past 8 quarters. The transition of interest is the persistence of the Current state, which gives some indication of whether the reform served as any kind of deterrent to delinquent behavior. Table 11 reports the analog of the analysis in the previous paragraph for this initial state. There is no evidence that the persistence of the current state was affected by the bankruptcy transition drop.

Table 11: Evidence on the effects of the reform: Substitution from Bankruptcy.

\begin{tabular}{lcc}
\hline Horizon & $4 \mathrm{Q}$ & $8 \mathrm{Q}$ \\
\hline & & Current to Current \\
\cline { 3 - 3 } \cline { 3 - 3 }$R^{2}$ & $0.003(1.08)$ & $0.007(1.47)$ \\
\hline
\end{tabular}

The estimates are obtained using robust regression to control for the effects of outliers. Horizon denotes the horizon of the outcome variable-flows to bankruptcy are kept at the 4 quarter horizon. Source: Authors' calculations based on Federal Reserve Bank of New York's Consumer Credit Panel/Equifax Data.

\section{Conclusions}

Our transition and regression analyses show a sizable substitution from bankruptcy to insolvency, with and without foreclosure, and a rise of the persistence of insolvency. We now compare Ch. 7 bankruptcy and insolvency without bankruptcy from the standpoint of credit scores and credit access. Therefore, the tradeoff is having a bankruptcy flag on one's credit 
record without any delinquent or insolvent debt, collections items or court judgements, versus no bankruptcy flag with an accumulation of delinquent and insolvent balances, with possibly additional derogatory items.

We adopt an event study approach, and, in each quarter, we examine two groups of individuals: (i) those who show a new insolvency on any type of debt after 8 quarters without insolvency bankruptcy or foreclosure (Newly Insolvent) or (ii) individuals who experience a new Chapter 7 bankruptcy (Bankrupt). Among the Newly Insolvent, we further distinguish between individuals who do not file for bankruptcy in the 8 quarters after the new insolvency (Non-Bankrupts), and those who do (Future Bankrupts).

We examine the differences in access to credit between individuals who become newly insolvent in a given quarter without bankruptcy in the next 8 quarters, and individuals who go bankrupt in that quarter.

We begin by describing the behavior of credit scores, since they are used as a proxy measure of creditworthiness by most lenders. Figure 9 (left panel) compares credit scores for the newly insolvents conditional on whether they go bankrupt in the next 8 quarters. At insolvency, those who will go bankrupt display a lower credit score, which suggests that they are negatively selected. Four quarters after the new insolvency, this ranking still prevails, even if credit scores have increased for both groups. Figure 9 (right panel) compares credit scores for the individuals who become newly insolvent in a given quarter who do not go bankrupt in the next 8 quarters, and individuals who go bankrupt in that quarter. Both one and four quarters after bankruptcy, the credit scores of the individuals who go bankrupt are considerably higher than those of the newly insolvent who do not go bankrupt. Moreover, this difference grows after the implementation of the reform, suggesting positive selection of bankrupt individuals in the post-reform period compared to bankrupt individuals in the pre-reform period. This change in the difference in credit score across bankrupt individuals and newly insolvent who will no go bankrupt is consistent with binding liquidity constraints prevent the newly insolvents from filing for bankruptcy.

Finally, figure 10 (left panel) displays the fraction of individuals with at least one new unsecured line of credit opened in the last year, four quarters after the new insolvency or bankruptcy. We interpret this as a measure of credit supply. In figure 10 (right panel), we also report the fraction of individuals with inquiries among these groups, also 4 quarters after insolvency or bankruptcy, an indicator of credit demand.

Clearly, bankrupt households are more successful opening new unsecured lines of credit, even though (until 2009) they submit inquiries at a similar rate as individuals who will not go bankrupt. Even with the considerable time variation in both series, the percentage difference 

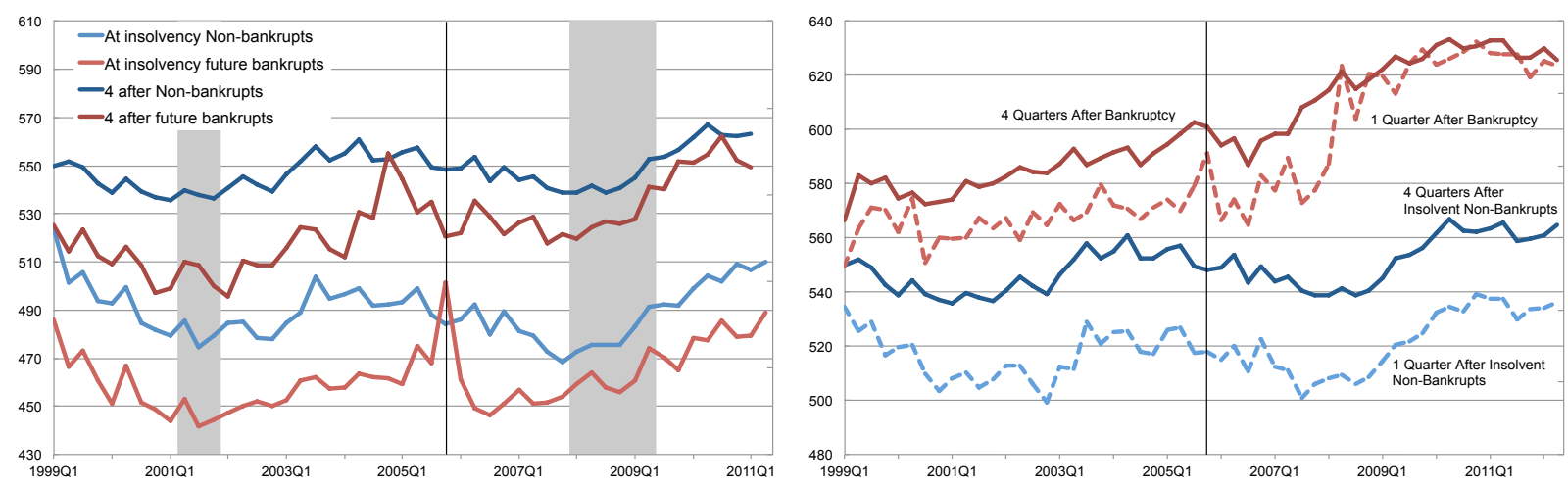

Figure 9: Credit scores of the newly insolvent by future bankruptcy status (left panel) and credit score after bankruptcy and after insolvency without bankruptcy (right panel), at various horizons. Source: Authors' calculation based on Federal Reserve Bank of New York's Consumer Credit Panel/Equifax Data.

in the fraction with new lines of credit between bankrupts and newly insolvent who do not go bankrupt is roughly stationary at $19 \% 23$ These results are consistent with Jagtiani and Li (2014), who study credit access after Ch. 7 and Ch. 13 bankruptcy in detail.
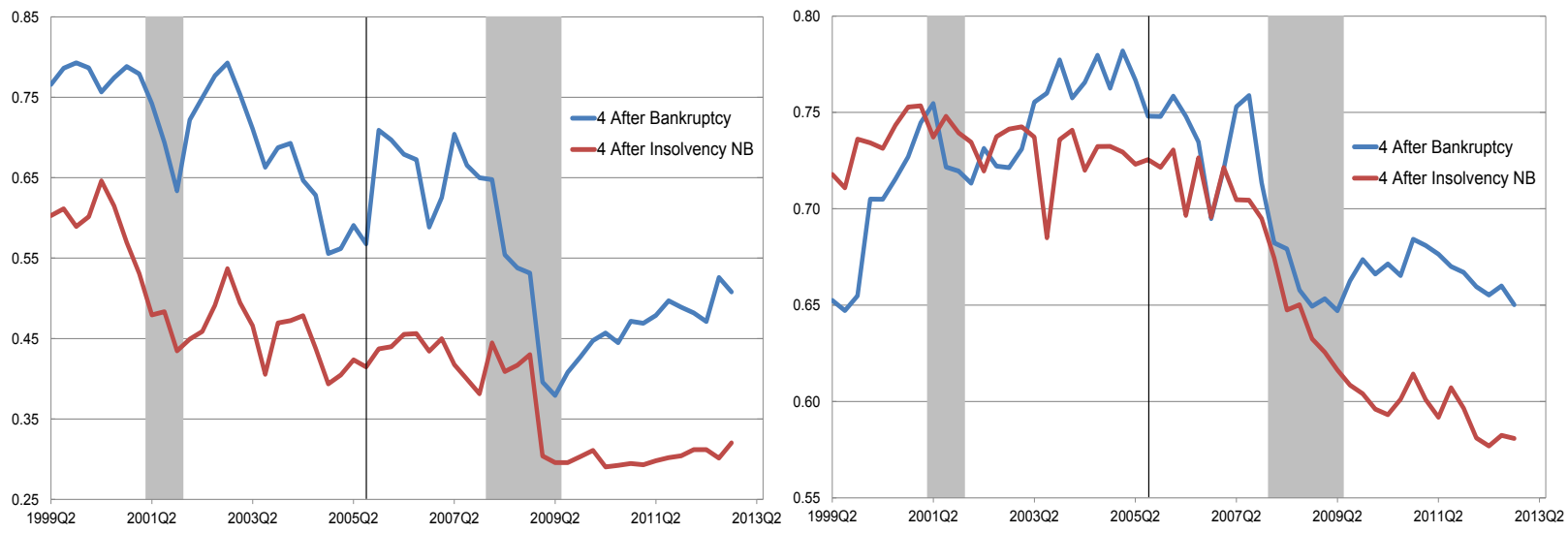

Figure 10: Fraction of Newly Insolvent without bankruptcy in the next 8 quarters and fraction of Bankrupts who opened at least one new unsecured line within the prior year (left panel) and with at least one inquiry (right panel). Source: Authors' calculation based on Federal Reserve Bank of New York's Consumer Credit Panel/Equifax Data.

Our analysis suggests that the 2005 bankruptcy reform caused a decline in bankruptcy filings, which were replaced by a sizable rise in insolvency and foreclosure. We show that

\footnotetext{
${ }^{23}$ The discontinuity in behavior may be due to the Credit Card Accountability Responsibility and Disclosure Act of 2009, which introduced improved standards of transparency and accountability for credit cards companies.
} 
insolvency is a state associated with a high degree of financial distress in comparison to bankruptcy ${ }^{24}$ This consequence of BAPCPA is potentially welfare reducing for households. However, since the recovery rates for creditors from insolvent loans are higher than on bankrupt loans, this could have induced banks and credit card companies to expand access and improve conditions for personal loans. Indeed, Simkovic (2009) finds that BAPCPA reduced credit card company losses and increased their profits. However, there is little evidence that credit conditions for consumers improved. Taken together, these findings suggest the main effect of the 2005 bankruptcy reform was to shift financially stressed individuals from bankruptcy to insolvency.

\footnotetext{
${ }^{24}$ This suggests that insolvency is on average more punishing for an individual's credit record than bankruptcy in most cases, and would not be a choice for most individuals, contrary to the notion proposed in Ausubel and Dawsey (2004).
} 


\section{References}

Athreya, Kartik B. 2002. "Welfare implications of the bankruptcy reform act of 1999." Journal of Monetary Economics 49 (8): 1567-1595.

Ausubel, Lawrence, and Amanda Dawsey. 2004. "Informal bankruptcy." Work. Pap., Dep. Econ., Univ. Maryland.

Carroll, Sarah W, and Wenli Li. 2011. "The homeownership experience of households in bankruptcy." Cityscape, pp. 113-134.

Domowitz, Ian, and Thomas L Eovaldi. 1993. "The Impact of the Bankruptcy Reform Act of 1978 on Consumer Bankruptcy." Journal of Law \& Economics 36:803.

Domowitz, Ian, and Robert L Sartain. 1999. "Determinants of the consumer bankruptcy decision." The Journal of Finance 54 (1): 403-420.

Eraslan, Hulya, Gizem Kosar, Wenli Li, and Pierre-Daniel G Sarte. 2014. "An anatomy of us Personal bankruptcy under chapter 13."

Fay, Scott, Erik Hurst, and Michelle J White. 2002. "The household bankruptcy decision." American Economic Review 92 (3): 706-718.

Gross, David B, and Nicholas S Souleles. 2002. "An empirical analysis of personal bankruptcy and delinquency." Review of Financial Studies 15 (1): 319-347.

Gross, Tal, Matthew J Notowidigdo, and Jialan Wang. 2012. "Liquidity constraints and consumer bankruptcy: Evidence from tax rebates." Review of Economics and Statistics, no. 00 .

Hynes, Richard M, Amanda E Dawsey, and Lawrence M Ausubel. 2009. "The Regulation of Non-Judicial Debt Collection and the Consumer's Choice among Repayment, Bankruptcy and Informal Bankruptcy." Virginia Law and Economics Research Paper, no. 2009-13.

Jagtiani, Julapa, and Wenli Li. 2014. "Credit access after consumer bankruptcy filing: new evidence."

Jones, Yvonne D. 2008. Bankruptcy Reform: Dollar Costs Associated with the Bankruptcy Abuse Prevention and Consumer Protection Act Of 2005. DIANE Publishing.

Lawless, Robert M., Angela K. Littwin, Katherine Porter, John Pottow, Deborah Thorne, and Elizabeth Warren. 2008. "Did bankruptcy reform fail? An empirical study of consumer debtors." American Bankruptcy Law Journal 82:349-406. 
Lee, Donghoon, and Wilbert van der Klaauw. 2010. "An Introduction to the FRBNY Consumer Credit Panel." FRBNY Staff Report 479.

Li, Wenli. 2009. "Residential housing and personal bankruptcy." Business Review $Q$ 2:19-29.

Livshits, Igor, James MacGee, and Michele Tertilt. 2007. "Consumer bankruptcy: A fresh start." The American Economic Review 97 (1): 402-418.

—. 2010. "Accounting for the Rise in Consumer Bankruptcies." American Economic Journal: Macroeconomics 2 (2): 165-193.

Lupica, Lois R. 2012. "The Consumer Bankruptcy Fee Study: Final Report." Am. Bankr. Inst. L. Rev. 20:17-759.

Mann, Ronald J, and Katherine Porter. 2009. "Saving up for Bankruptcy." Geo. LJ 98:289.

Morgan, Donald P, Benjamin Charles Iverson, and Matthew J Botsch. 2012. "Subprime foreclosures and the 2005 bankruptcy reform." Economic Policy Review, March.

Morgan, Donald P, and Michael R Strain. 2007. "Staff Reports."

Norberg, Scott, and Andrew Velkey. 2007. "What Do We Know About Chapter 13 Personal Bankruptcy Filings?" manuscript.

White, Michelle J. 2007. "Bankruptcy reform and credit cards." NBER Working Paper 13265.

White, Michelle J, and Ning Zhu. 2008. "Saving Your Home in Bankruptcy." 


\section{A Consumer Credit Panel Data and Variables}

\section{Transition Matrices}

Our transition matrices include 14 possible states: seven debt states for individuals who are not in foreclosure, and seven debt states for individuals who are in foreclosure. We define the seven debt states and foreclosure as follows:

1. Delinquent: An individual is delinquent if they have at least one loan in their CCP report in that quarter that is 30,60 , or 90 days past due (crtr_attr13, crtr_attr14, or crtr_attr15), while not having any loans that are $120+$ days past due, severely derogatory, or bankrupt (crtr_attr16, crtr_attr17, or crtr_attr18). Also, at least one of crtr_attr16, crtr_attr17, or crtr_attr18 must be non-missing, and the individual must not be in a state of bankruptcy.

2. Insolvent: An individual is insolvent if they have at least one loan in their CCP report in that quarter that is $120+$ days past due, severely derogatory, or bankrupt (crtr_attr16, crtr_attr17, or crtr_attr18), while not having any loans that are 30, 60, or 90 days past due (crtr_attr13, crtr_attr14, or crtr_attr15). Also, at least one of crtr_attr13, crtr_attr14, or crtr_attr15 must be non-missing, and the individual must not be in a state of bankruptcy.

3. Both: An individual is both delinquent and insolvent if they both have at least one loan in their CCP report in that quarter that is 30,60, or 90 days past due (crtr_attr13, crtr_attr14, or crtr_attr15) and have at least one loan in their CCP report in that quarter that is $120+$ days past due, severely derogatory, or bankrupt (crtr_attr16, crtr_attr17, or crtr_attr18). Also, at least one of crtr_attr13, crtr_attr14, or crtr_attr15 and one of crtr_attr16, crtr_attr17, or crtr_attr18 must be non-missing, and the individual must not be in a state of bankruptcy.

4. Neither: An individual is neither delinquent nor insolvent if they have no loans that are 30,60, 90 or 120+ days past due, severely derogatory, or bankrupt (crtr_attr13, crtr_attr14, crtr_attr15, crtr_attr16, crtr_attr17, or crtr_attr18). Also, at least one of crtr_attr13, crtr_attr14, or crtr_attr15 and one of crtr_attr16, crtr_attr17, or crtr_attr18 must be non-missing, and the individual must not be in a state of bankruptcy.

5. Missing: An individual's debt status is missing if the number of loans in their CCP report in that quarter that are 30,60, or 90 days past due (crtr_attr13, crtr_attr14, or crtr_attr15) are all not reported, or the number of loans that are 120+ days past due, severely derogatory, or bankrupt (crtr_attr16, crtr_attr17, or crtr_attr18) are all not reported. Nonreporting occurs when Equifax does not receive enough information from the respective financial institutions to generate its credit trend variables.

6. Chapter 7 Bankruptcy: There are two scenarios in which an individual is identified as being in the state of Chapter 7 bankruptcy. First, if the individual experiences Chapter 7 bankruptcy commencement (see below), then that individual is marked as being in a state of Chapter 7 bankruptcy for ten years after the date of their foreclosure. Second, if the individual enters the dataset for the first time marked with the bankruptcy flag (cust_attr290) 
coded "Chapter 7 discharged" (which almost exclusively occurs at the datasets 1999 Q1 truncation), that individual is marked as being in the state of Chapter7 bankruptcy until the flag (which is supposed to stay on for ten years after the bankruptcy's commencement) turns off. We define the commencement of Chapter 7 bankruptcy as the following pattern in cust_attr290: the individual is marked as Chapter 7 discharged in the present quarter, Chapter 7 voluntary or Chapter 7 involuntary in the most recent past quarter, and Chapter 7 discharged in the next quarter.

7. Chapter 13 Bankruptcy: There are two scenarios in which an individual is identified as being in the state of Chapter 13 bankruptcy. First, if the individual experiences Chapter 13 bankruptcy commencement (see below), then that individual is marked as being in a state of Chapter 13 bankruptcy for ten years after the date of their foreclosure. Second, if the individual enters the dataset for the first time marked with the bankruptcy flag (cust_attr291) coded "Chapter 13 discharged" (which almost exclusively occurs at the datasets 1999 Q1 truncation), that individual is marked as being in the state of Chapter13 bankruptcy until the flag turns off. We define the commencement of Chapter 13 bankruptcy as the following pattern in cust_attr291: the individual is marked as Chapter 13 discharged in the present quarter, Chapter 13 filed in the most recent past quarter, and chapter 13 discharged in the next quarter.

- Foreclosure: There are two scenarios in which an individual is marked as being in the state of foreclosure. First, if the individual forecloses on a home (that is, if cma_attr3905 switches from off ("0") to on ("1" or "7")), then that individual is marked as being in a state of foreclosure for seven years after the date of their foreclosure. Second, if the individual enters the dataset for the first time while under foreclosure (which almost exclusively occurs at the datasets 1999 Q1 truncation), that individual is marked as being in the state of foreclosure until the flag (which is supposed to stay on for seven years after the date of the foreclosure) turns off.

We condition transition matrices on credit score quintile using the CCP Equifax risk score, which is similar to the FICO score, in that both model 24 month default risk as a function of credit report measures (see Lee and van der Klaauw (2010)). It varies between 280 and 840 and represents an assessment of the individuals credit-worthiness. We also condition transition matrices using four different definitions of homeownership:

- Less-Restrictive Current Homeownership: The individual has at least one home-secured loan in the given quarter (using crtr_attr6, crtr_attr7, and crtr_attr8).

- More-Restrictive Current Homeownership: The individual has at least one mortgage loan in the given quarter (using crtr_attr6).

- Less-Restrictive Overall Homeownership: The individual has at least one home-secured loan at any time between 1999 and 2013 in the CCP dataset (using crtr_attr6, crtr_attr7, and crtr_attr8).

- More-Restrictive Overall Homeownership: The individual has at least one mortgage loan at any time between 1999 and 2013 in the CCP dataset (using crtr_attr6). 
Regressions

Our regression analysis models three variables of interest:

1. Bankruptcy Rate: The fraction of CCP-covered individuals who commence Chapter 7 bankruptcy, by judicial district and quarter. We define the commencement of Chapter 7 bankruptcy as the following pattern in cust_attr290: the individual is marked as Chapter 7 discharged in the present quarter, Chapter 7 voluntary or Chapter 7 involuntary in the most recent past quarter, and Chapter 7 discharged in the next quarter. We exclude districts in which the average number of bankruptcies per quarter in the CCP is fewer than 5 .

2. Foreclosure Rate: The fraction of CCP-covered individuals who enter the state of foreclosure, by judicial district and quarter. We define the state of foreclosure as a quarter in which the indicator cma_attr3905 is on ("1" or "7").

3. Insolvency Rate: The fraction of CCP-covered individuals who enter the broad state of insolvency, by judicial district and quarter. An individual is broadly insolvent if they have at least one loan in their CCP report in that quarter that is $120+$ days past due, severely derogatory, or bankrupt (crtr_attr16, crtr_attr17, or crtr_attr18).

The variable of interest in our regression analysis is the "average attorney fee by district for discharged no-asset Chapter 7 cases adjusted for inflation (including converted cases)," Table A-23 of Lupica (2011). The other covariates include:

1. Income: Annual county-level income data for 3,142 counties are drawn from the Internal Revenue Services (IRS) Statistics of Income program, which annually aggregates household-level adjusted gross income as reported on US tax forms. We calculate income at the district level as the weighted average of the average income in counties covered by that district, using the CCP district populations as weights.

2. Unemployment Rate: Annual county-level unemployment data are drawn from the Bureau of Labor Statisticss (BLS) Local Area Unemployment Statistics program. The unemployment data are reported on a monthly basis, and they cover a total of 3,145 counties. We calculate the unemployment rate at the district level as the weighted average of the average unemployment rate in counties covered by that district, using the CCP district populations as weights.

3. House Price Index: House Price Index (HPI) values are drawn at the zip code level from the CoreLogic HPI. The CoreLogic HPI uses repeat sales transactions to track changes in sale prices for homes over time, with the January 2000 baseline receiving a value of 100, and it is the most comprehensive monthly house price index available. The CoreLogic data cover a total of 6739 zip codes (representing 58 percent of the total U.S. population) in all 50 states and the District of Columbia. We calculate the HPI at the district level as the weighted average of the average HPI in zip codes covered by that district, using the CCP district populations as weights.

4. Wage Garnishment: Wage garnishment laws specify the amount of an individual's wage that may not be garnished by judgment creditors to repay debt. States either adopt 
federal wage garnishment restrictions-the lesser of (a) 75 percent of the employee's disposable earnings or (b) 30 times the federal minimum wage-or adopt their own stricter restrictions. We calculate our proxied wage garnishment covariate by estimating the wage level protected from wage garnishment under two scenarios, the minimum wage scenario and the average wage scenario. Under the minimum wage scenario, states are bound either by a multiple of the minimum wage or, in states that only designate a percentage of total income, by that percentage of estimated average income, where estimated average income is the 40-hour minimum wage over 0.298 , the average ratio between 40 -hour minimum wage and average income (drawn from the IRS's Statistics of Income program) across states. Under the average wage scenario, states are bound by either the designated percentage of their average wage or, in states that only specify a minimum wage, by the the designated multiple of estiamted minimum wage, calculated as the average wage times 0.298 . These methods rank states very similarly. We take the minimum of the two estimates as our wage garnishment covariate.

5. Judicial State Indicator: An indicator for whether the state requires that all foreclosures be judicial (where judicial states are coded as 1).

6. Recourse State Indicator: An indicator for whether the state is a recourse state regarding mortgages (where recourse states are coded as 1).

7. Homestead Exemption: Homestead exemption laws specify the maximum value of primary residences that are generally shielded from debt repayment to judgment creditors. We use homestead exemption values collected in Table 1 of Rohlin and Ross (2013), extrapolating the exemption from 1999 to 2005 Q2 as the 2004 exemption and the exemption from 2005Q3 to 2013 as the 2006 exemption.

\section{Event Studies}

Our event studies, in addition to the states described above (bankruptcy, insolvency, etc.), measure the following debt characteristics of covered individuals:

1. New secured (unsecured) debt: We calculate the total number of originated secured (unsecured) loans by differencing one's current number of loans by type with the number of loans of that type had in the previous quarter, with a minimum value of 0 , using crtr_attr2, crtr_attr3, crtr_attr6, crtr_attr7, and crtr_attr8 (crtr_attr4, crtr_attr5, crtr_attr9). We then sum the number of loan originations over the current quarter and the past three quarters.

2. Has Collection: An indicator for whether an individual currently has at least one collection account (generated using cma_attr3909).

3. Collections Balance: The total balance of an individuals' collection accounts, conditional on their having at least one collection account (generated using cma_attr13).

4. Has Judgment: An indicator for whether an individual has experienced a "judgment public record item" within the past 7 years (generated using cma_attr3813).

5. Age Judgment: The number of months since an individual's most recent "judgment public record item", conditional on their having had at least one such judgment in the past seven years (generated using cma_attr3813). 
6. Has Inquiry: An indicator for whether an individual has made at least one loan inquiry (a "hard pull" of one's credit report) in the past 12 months (generated using cma_attr3001).

\section{B Income Data and Imputation}

\section{B.1 Linked Payroll Data}

In this section, we describe the supplementary payroll data from a large income verification firm for 2009 which we use at various stages of our income imputation procedure. This data is merged with our credit panel data, allowing us to map individuals' incomes for 2009 to their credit files.

The data is derived from a large nationally representative income verification firm. The information provided for each employee includes the last three years of total income, the date of first hire, tenure, and for the current year status (part time/full time), weekly hours, pay rate and pay frequency. To measure income, we use an imputed measure of total income obtained by computing pay rate times pay frequency, expressed in annual terms, yielding about 11,000 observations for 2009 ${ }^{25}$ The sample of records is nationally representative, both in terms of geographical and age distribution. The resulting income measure is comparable in distribution to the CPS and the American Community Survey.

We compare individuals' incomes by credit score distribution, as well as the distribution of income distributions by homeownership status. Our evidence shows that low credit scores and non-homeownership are strong predictors of low income.

Table 12 provides information on the income distribution by credit score quintile. Each entry displays the probability of being in a given income quintile, for individuals in a given credit score quintile. Individuals in the first credit score quintile have a $36 \%$ probability of being in the first income quintile, and a $62 \%$ probability of being in the first two quintiles of the income distribution. By contrast, individuals in the top quintile of the income distribution have a $42 \%$ probability of being in the top income quintile.

Table 13 provides information on the income distribution by homeownership status. Current homeowners' probability of being in the lowest income quintile is $10 \%$, while it is $34 \%$ for current non-homeowners. By contrast, current homeowners' probability of being in the top two income quintiles in $57 \%$, while it is only $21 \%$ for non-homeowners.

\section{B.2 Imputation Procedure}

Our imputation procedure relies on the Survey of Consumer Finances, and uses the TALX data discussed above for verification. Our goal is to assign individuals to income quartiles. To do so, for each year in which the SCF is available in our sample period (2001-2012), we estimate the following regression:

$$
y_{t}^{i}=\beta_{0}+\beta_{1} X_{t}^{i}+\beta_{2} \times a g e+\beta_{3} \times a g e^{2}+\varepsilon_{t}^{i},
$$

\footnotetext{
${ }^{25}$ For the observations that have both reported total income and pay rate and frequency, our imputed measure matches total income very well.
} 
Table 12: Distribution of Income by Credit Score Quintile

\begin{tabular}{lllllll}
\hline Income Quintile & 1 & 2 & 3 & 4 & 5 & Count \\
\hline CS Quintile & & & & & & \\
1 & 0.36 & 0.26 & 0.20 & 0.12 & 0.05 & 1707 \\
2 & 0.31 & 0.25 & 0.24 & 0.15 & 0.05 & 1949 \\
3 & 0.27 & 0.20 & 0.21 & 0.20 & 0.12 & 2158 \\
4 & 0.13 & 0.15 & 0.21 & 0.24 & 0.26 & 2300 \\
5 & 0.08 & 0.09 & 0.17 & 0.23 & 0.42 & 2483 \\
\hline
\end{tabular}

Source: Authors' calculation based on Federal Reserve Bank of New York's Consumer Credit Panel/Equifax Data.

Table 13: Distribution of Income by Current Homeownership Status

\begin{tabular}{|c|c|c|c|c|c|c|}
\hline Income Quintile & 1 & 2 & 3 & 4 & 5 & Count \\
\hline $\begin{array}{l}\text { Current Home- } \\
\text { owner }\end{array}$ & & & & & & \\
\hline 0 & 0.34 & 0.24 & 0.20 & 0.13 & 0.08 & 5153 \\
\hline 1 & 0.1 & 0.12 & 0.21 & 0.26 & 0.31 & 5444 \\
\hline
\end{tabular}

Source: Authors' calculation based on Federal Reserve Bank of New York's Consumer Credit Panel/Equifax Data.

where $y_{t}^{i}$ is labor income in 2012 dollars, $X_{t}^{i}$ is a vector corresponding to the quantile in the debt balance distribution for unsecured debt, real estate debt, auto debt, and student loans, conditional on having strictly positive debt in those category, plus an indicator variable for zero debt in each of those categories. We estimate this equation for each release of the SCF, specifically 2001, 2004, 2007, 2008, 2009 and 2010. We take the estimated coefficients and apply them to the individuals in our Equifax sample, to obtain a predicted value of $y_{t}^{i}$. Since our data is quarterly, we apply these coefficients every quarter, and maintain the coefficients constant until a new release of the SCF becomes available. For each quarter, we rank the predicted values of $y_{t}^{i}$ for the Equifax sample to assign individuals to quartiles of the predicted income distribution.

We use debt quintiles instead of levels to minimize the effects of trend growth in debt during the sample period on the income imputation. Even with this strategy, the estimated coefficients exhibit some time variation across SCF survey years, suggesting time variation in the relation between debt portfolio and income driven by financial innovation and other factors.

To verify the quality of our income imputation procedure we use the 2009 payroll data linked to Equifax, and for each SCF year we perform an in sample verification. We find that our imputation procedure performs very well in assigning individuals to the first and 
fourth quartile, and is slightly more inaccurate in assigning individuals to the second and third quartile.

Figure 11 presents the results of this verification for the $2010 \mathrm{SCF}$. The figure presents the probability of being in imputed income quartile 1 to 4 (from left to right) for individuals with income in quartile 1 to 4 .

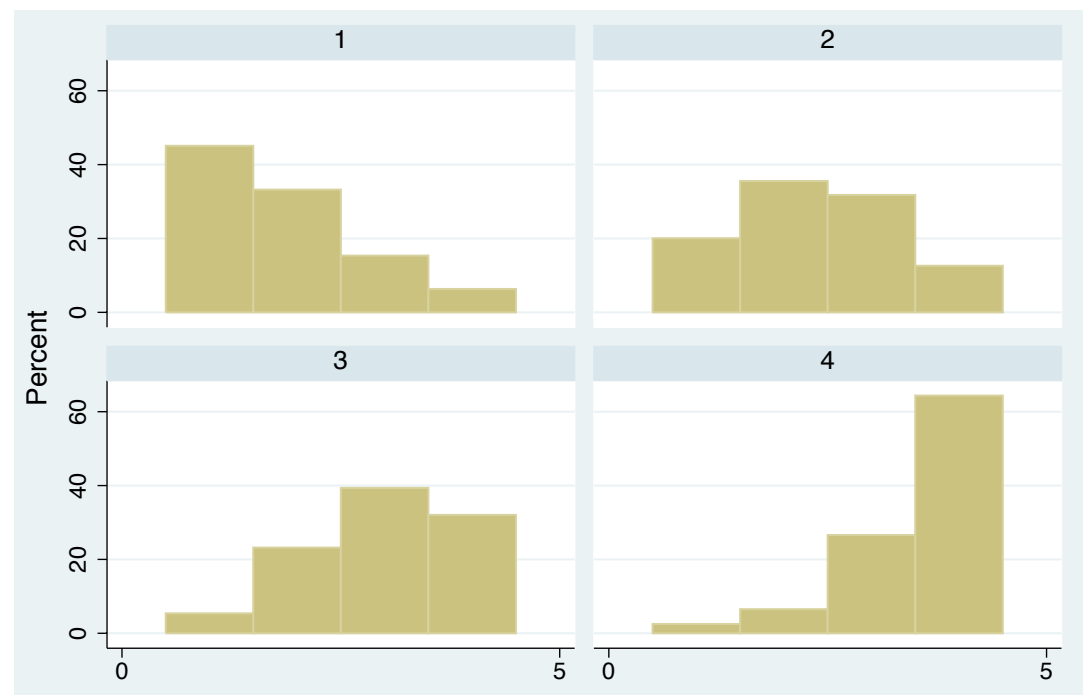

Figure 11: Percentage of individuals in each income quartile with imputed income in quartiles 1-4 (left to right) for 2010. Source: Authors' calculations using the Survey of Consumer Finances 2010.

\section{IV Regressions}

\section{C.1 Judge Preference Instrument}

We report some properties of the Judge Preference instrument. We start with exogeneity, by reporting in figure 12 the percentage change in the fraction of appellate court magistrates appointed by a republican president between 1993 and 2001 (the eight year Clinton presidency) and between 2001 and 2009 (the eight year presidency of G.W. Bush). As can be clearly seen from figure 12 the percentage of republican appointed judges falls under President Clinton in all circuits (by $-35 \%$ to $-15 \%$ ) and rises under President Bush in all circuits (from $14 \%$ to $32 \%$ ).

We also show that our instrument is not correlated with local preferences at the district level, which could drive both the attorney fee change and bankruptcy outcomes via their influence on local culture or judicial norms. This is illustrated in figure 13 , where we report 
Percent Change in the Proportion of Circuit Judges Holding a Seat in 2001

Appointed by a Republican President, by United States Appellate Court
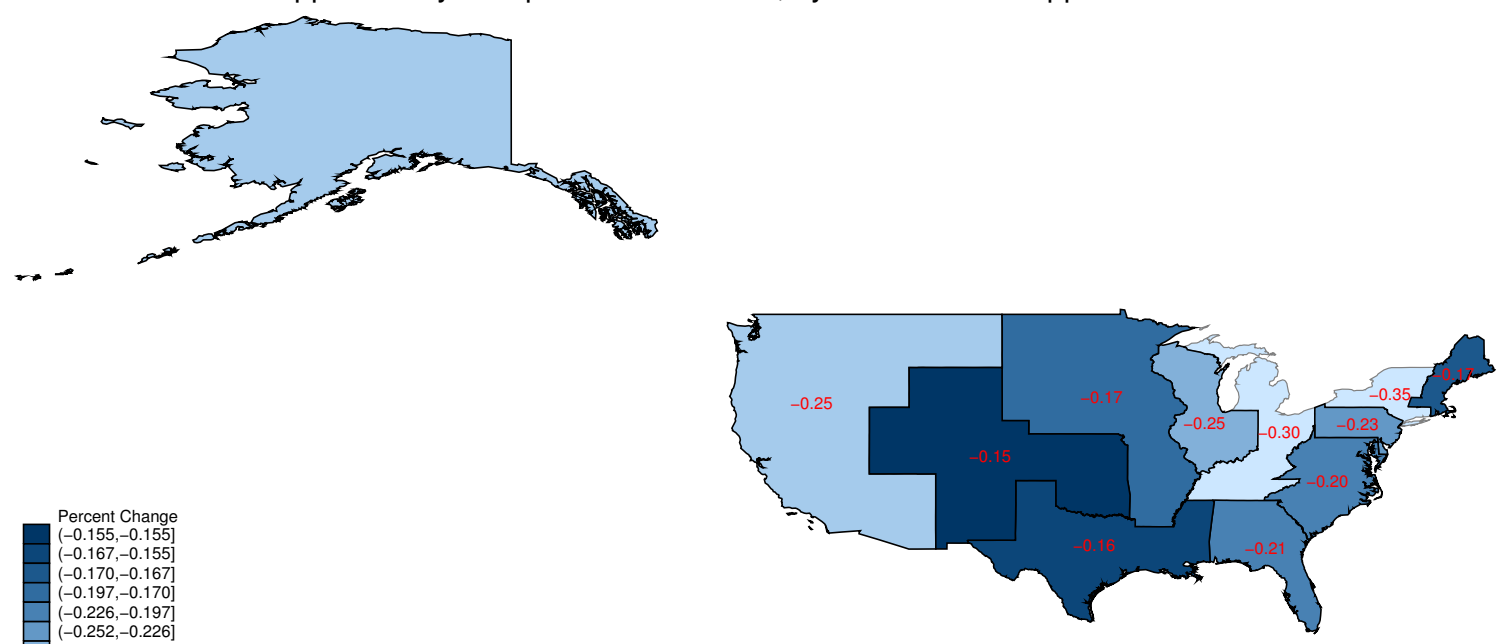

Percent Change in the Proportion of Circuit Judges Holding a Seat in 2009

Appointed by a Republican President, by United States Appellate Court

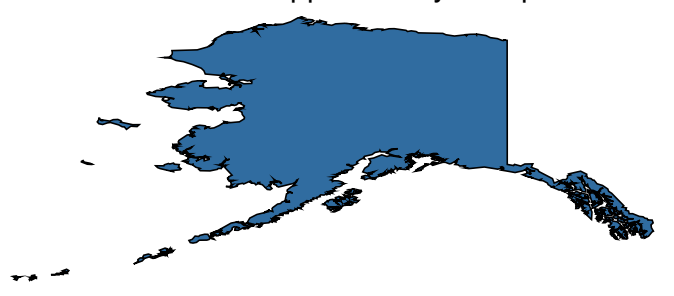

$$
\begin{aligned}
& \text { Percent Change } \\
& (0.260,0.325] \\
& (0.249,0.260] \\
& (0.241,0.249] \\
& (0.233,0.241] \\
& (0.185,0.23] \\
& (0.176,0.185] \\
& (0.176,0.176] \\
& 0.163,0.176] \\
& {[0.142,0.163]}
\end{aligned}
$$

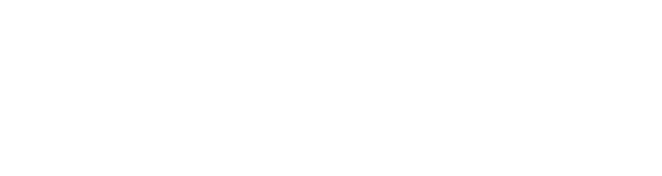

Figure 12: Change in the percentage of magistrates on the Court of Appeals appointed by Republican presidents during the Clinton (1993-2001, top panel) and G.W. Bush (2001-2009, bottom panel) administrations, in each Circuit.

the distribution of our instrument across court districts (top panel) and the proportion of the popular vote for the republican candidate in the 2004 presidential election (bottom panel). 
The correlation between these two variables is -0.03 and not significantly different from zero.

Proportion of Bankruptcy Judges Appointed by Republican-Nominated Circuit Judges by United States Court District

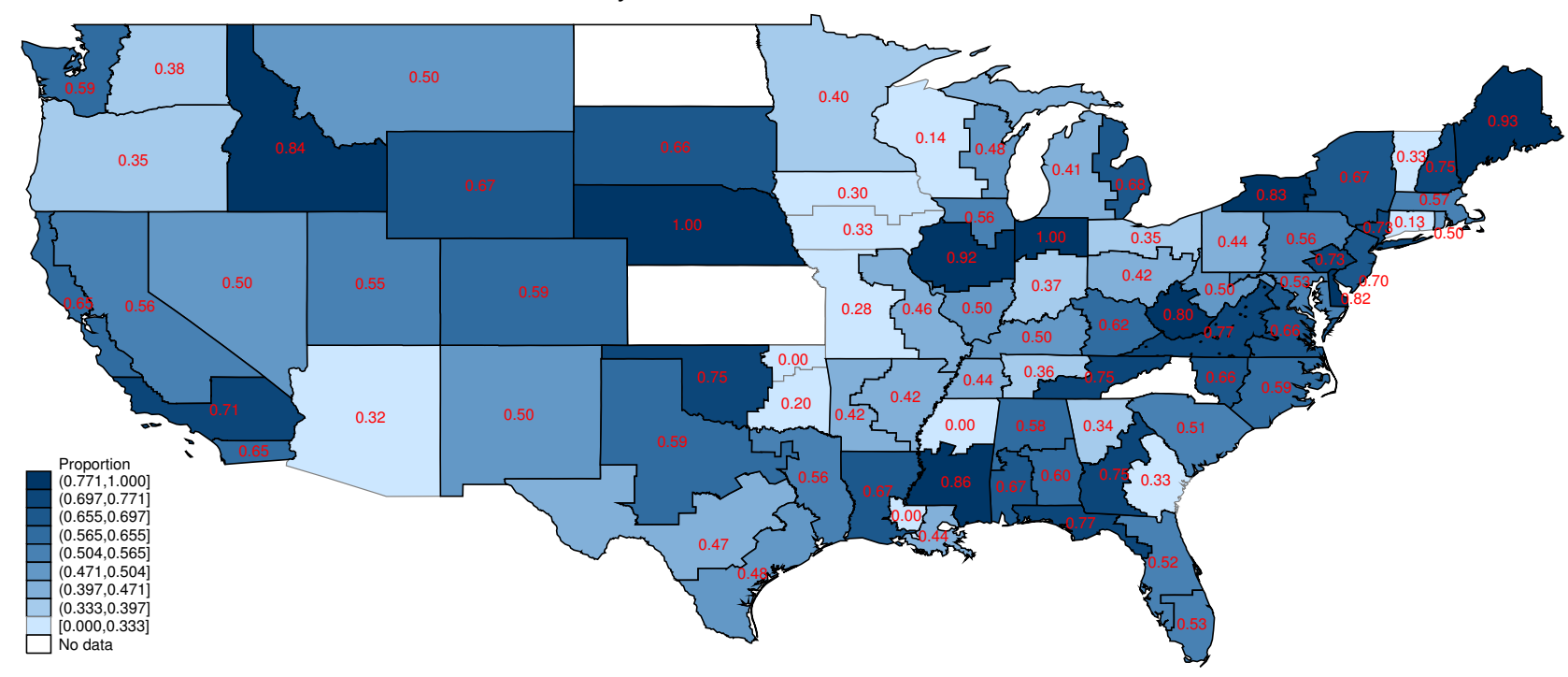

Proportion of Popular Votes for Republican President in the 2004 Presidential Election by State

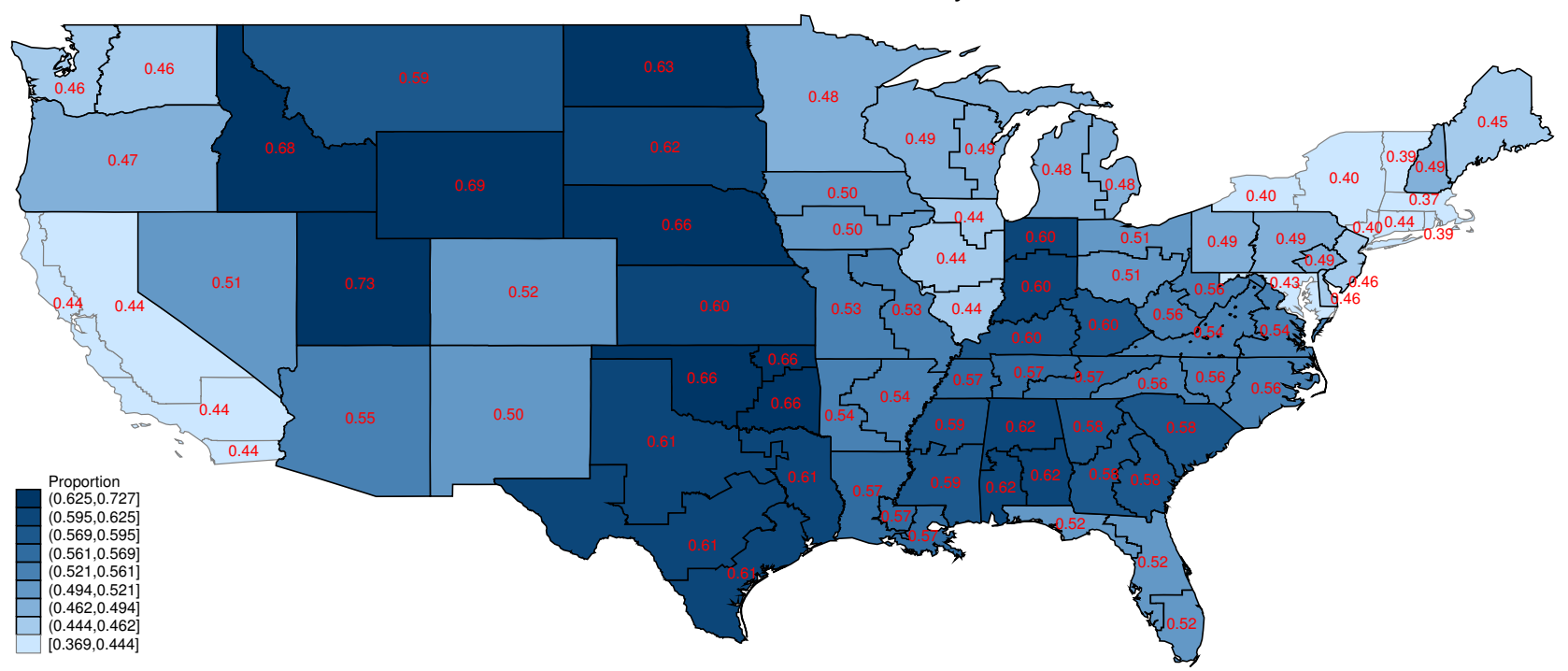

Figure 13: Political preference of bankruptcy courts in 2004 (top panel) and proportion of the popular vote for the republican candidate in the 2004 presidential elections (bottom panel). Source for bottom panel: Federal Election Commision. 